\title{
Half-Heusler Compounds: Promising Materials For Mid-To-High Temperature Thermoelectric Conversion
}

\section{S. Joseph Poon}

Department of Physics, University of Virginia, Charlottesville, VA 22904-4714, USA

\begin{abstract}
Half-Heusler compounds (space group $\mathrm{Fm} \overline{3} \mathrm{~m}$ ) have garnered increasing attention in recent years in the thermoelectric community. Three decades ago, refractory RNiSn half-Heusler compounds ( $\mathrm{R}$ represents refractory metals such as $\mathrm{Hf}, \mathrm{Zr}$, Ti) were found to be narrow-gap semiconductors with large Seebeck coefficients in 100s of micro-volt per Kelvin. Today, half-Heusler (HH) compounds have emerged as promising thermoelectric materials in the intermediate temperature range $\left(400-800^{\circ} \mathrm{C}\right)$. $\mathrm{HH}$ materials are endowed with good thermal stability and scalability. Thermoelectric n-p modules based on $\mathrm{HH}$ materials demonstrate conversion efficiency near $10 \%$ and power density output near $9 \mathrm{~W} / \mathrm{cm}^{2}$. The objective of this article is to present a historical account of the research and development of thermoelectric half-Heusler compounds. Particularly, there have been notable achievements since 2012 thanks to the emergence of new approaches. As a result, ZT has risen from $\sim 1$ to 1.5 . The various advances made since the early 1990 s to the present are recounted by categorizing half-Heusler materials into three generations (Gen): Gen-1 Gen-2, and Gen-3 HH materials.
\end{abstract}




\section{Introduction}

More than half of the global energy produced from available sources is wasted, mostly in the form of heat ${ }^{1}$. The loss of useful energy amounts to a significant portion of the global GDP. To date, converting waste heat into useful energy is a major challenge due to low efficiency and high cost. The opportunities for waste heat recovery can be categorized according to the temperature ranges of the waste heat sources into the following areas ${ }^{2}$ : (i) low-grade heat harvesting $\left(450^{\circ} \mathrm{F} / 232^{\circ} \mathrm{C}\right.$ and lower) from, e.g., power plants, buildings, household utilities, computing centers, sea water, and geothermal sources; (ii) medium-grade $\left(450^{\circ} \mathrm{F} / 232^{\circ} \mathrm{C}\right.$ to $\left.1,200^{\circ} \mathrm{F} / 650^{\circ} \mathrm{C}\right)$ to high-grade $\left(1,200^{\circ} \mathrm{F} / 650^{\circ} \mathrm{C}\right.$ and higher) heat harvesting from, e.g., vehicle and jet engines as well as industrial plants. An energy harvest device based on thermoelectric (TE) materials can convert waste heat directly into electricity ${ }^{3}$. The device is all solid state, has no moving parts, and is portable. TE conversion technology is among the simplest direct energy conversion technologies, while leaving a minimal negative impact on the environment. TE devices are portable and can conveniently be integrated with other energy-conversion technologies. Critical to the TE devices development is the provision of high-performance thermoelectric materials.

A class of thermoelectric materials known as half-Heusler compounds (space group Fm $\overline{3} \mathrm{~m}$ ) have gained much attention in recent years in the thermoelectric community. In particular, the RNiSn-type half-Heusler compounds $(\mathrm{R}=\mathrm{Hf}, \mathrm{Zr}$, Ti) were first reported to be narrow-gap semiconductors by Aliev and co-workers three decades $\mathrm{ago}^{4,5,6}$. These authors measured a bandgap of about $0.2 \mathrm{eV}$ in optical and electrical transport experiments. They also reported a large n-type Seebeck coefficient on the order of a couple hundred micro-volts per degree Kelvin. The finding of large thermopower in RNiSn compounds apparently did not garner much attention until the mid-1990s when Cook et $\mathrm{al}^{7}$ and Kloc et $\mathrm{al}^{8}$ reported large thermopowers in excess of $-300 \mu \mathrm{V} / \mathrm{K}$ in some well-crystallized RNiSn samples. Investigation of the origin of bandgap in these metalbased semiconductors was performed by Ogut and Rabe in $1995^{9}$. The latter authors identified the important role of pd hybridization and dd interaction in forming the bandgap.

The goal of this article is to review the research and development of thermoelectric halfHeusler $(\mathrm{HH})$ compounds in the last three decades. In particular, the last decade has seen a rapid development of half-Heusler compounds thanks to the implementation of new synthesis methods and interdisciplinary approaches. Particularly since 2013, the dimensionless figure of merit, ZT, an important measure of thermoelectric performance, has risen rapidly from 1 to $\sim 1.5$. The advances made in different stages of development are remarkable. Accordingly, we have structured this review chronologically around three categories of thermoelectric half-Heusler materials, hereafter referred to as Gen-1 Gen-2, and Gen-3 HH materials (Gen is an abbreviation for Generation).

\section{Background}

\subsection{Basics of thermoelectric figure of merit}

The thermoelectric dimensionless figure of merit, $\mathrm{ZT}$, is defined as $\mathrm{ZT}=\left(\mathrm{S}^{2} \sigma / \kappa\right) \mathrm{T}$, where $\mathrm{S}$ is the Seebeck coefficient, $\sigma$ is the electrical conductivity, and $\kappa$ is the thermal conductivity ${ }^{3} . \kappa$ is the sum of $\kappa_{\mathrm{e}}$ and $\kappa_{\mathrm{L}}$, electronic contribution and lattice contribution to $\kappa$, respectively. $\kappa_{\mathrm{e}}$ is in turn 
related to $\sigma$ via the expression $\kappa_{\mathrm{e}}=L \sigma \mathrm{T}$, where $L$ is the Lorenz number. $\mathrm{S}^{2} \sigma$ is the power factor (PF). Some authors defined PF as $\mathrm{S}^{2} \sigma \mathrm{T}$, in which case, PF has the same dimension as $\kappa$ (in W/m$\mathrm{K})$. For clarification purpose, we will use $\mathrm{PF}^{*} \mathrm{~T}$, the power factor temperature product, in the latter definition. Alternatively, ZT can be written as follows:

$$
\mathrm{ZT}=\frac{\mathrm{S}^{2} / L}{\kappa_{\mathrm{L}} /(L \sigma \mathrm{T})+1}
$$

Assuming a single carrier-type model (e.g., n-type), then $\sigma=n q \mu_{c}$, and $S \sim m_{d}^{*} T / n^{2 / 3}$ as approximated using the Mott's formula ${ }^{10}$, where $\mu_{\mathrm{c}}$ is the carrier mobility, and $\mathrm{m}_{\mathrm{d}}^{*}$ is the total density of states (DOS). Direct substitution of these microscopic electronic bandstructure and transport parameters in equation (1) reveals that in order to enhance $\mathrm{ZT}$, the parameters $\mathrm{m}_{\mathrm{d}}^{*}$, $\mu_{\mathrm{c}}$, and $\mathrm{T}$ must be increased while $\kappa_{\mathrm{L}}$ must be decreased. These requirements are encapsulated in the quality factor known as $\mathrm{B}$ factor ${ }^{11}$ expressed as follows:

$$
\mathrm{B} \sim \mu_{\mathrm{c}} \mathrm{m}_{\mathrm{d}}^{* 3 / 2} \mathrm{~T}^{5 / 2} / \kappa_{\mathrm{L}}
$$

Equation (2) infers that the electronic and lattice properties can be independently controlled to increase B and thus ZT. However, the real situation is more complex. This is because $\mu_{\mathrm{c}}$ also depends on the effective mass, as follows:

$$
\mu_{\mathrm{c}} \sim \frac{1}{\mathrm{~m}_{\mathrm{c}}^{*} \mathrm{~m}_{\mathrm{b}}^{* 3 / 2} \varepsilon^{2}}
$$

where $m_{c}^{*}$ and $m_{b}^{*}$ are the conductivity effective mass and single-valley DOS effective mass, respectively. The effective masses mentioned are related to each other. In fact, $\mathrm{m}_{\mathrm{d}}^{*}$ is given by $\mathrm{N}_{\mathrm{V}}^{2 / 3} \mathrm{~m}_{\mathrm{b}}^{*}$, where $\mathrm{N}_{\mathrm{V}}$ is the valley degeneracy. The scaling relation in equation (2) can be rewritten as $\mathrm{B} \sim \mathrm{N}_{\mathrm{V}} \mathrm{T}^{5 / 2} / \mathrm{m}_{\mathrm{c}}^{*} \varepsilon^{2} \kappa_{\mathrm{L}}$. The band degeneracy therefore stands out as an important electronic factor for improving TE performance. $\varepsilon$ is the acoustic deformation potential for carrier scattering from phonons. A large $\varepsilon$ would reduce $\mu_{c}$, while also lowering $\kappa_{\mathrm{L}}$. The latter can also be reduced by other scattering mechanisms. As a result, one can strategically design composition and microstructure to separately control the electronic and phonon transport properties.

\subsection{Half-Heusler compounds, crystal structure and composition}

Heusler compounds are among the best known intermetallic compounds. The compositions of Heusler compounds are represented by the chemical formula $\mathrm{XY}_{2} \mathrm{Z}$ for full-Heusler compounds and $\mathrm{XYZ}$ for half-Heusler compounds, respectively, where $\mathrm{X}$ and $\mathrm{Y}$ are metals, and $\mathrm{Z}$ is a main

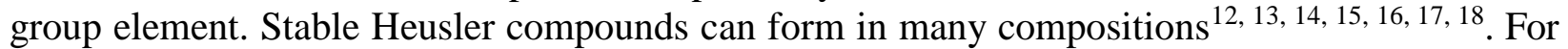
most of the Heusler compounds studied to date, $\mathrm{X}$ is either a transition metal, a lanthanide metal, or a noble metal, and $\mathrm{Y}$ is a transition metal or noble metal. The crystal structure of the full-Heusler (FH) compounds is of the L2 1 type (space group Fm $\overline{3} \mathrm{~m}$ ) consisting of four interpenetrating facecentered cubic (fcc) sublattices, each fully occupied by atoms. If one of the two Y sublattices is vacant, the crystal structure becomes that of the half-Heusler $(\mathrm{HH})$ compound $\left(\mathrm{C} 1_{\mathrm{b}}\right.$ type, space group $\mathrm{F} \overline{4} 3 \mathrm{~m}$ ), as shown in Figure 1. FH and $\mathrm{HH}$ compounds are known for their multifunctional 
properties that include semiconductor bandgap, half-metallic ferromagnetism, superconductivity, topological surface states, piezoelectricity, and shape memory effect just to name a few ${ }^{17}$.

Half-Heusler compounds have been synthesized by many research groups worldwide. Sample fabrication is relatively uncomplicated and production in kilogram quantity has been demonstrated ${ }^{19}$. Since the late 1990 s, half-Heusler alloys have garnered much attention as prospective thermoelectric materials for mid-to-high temperature energy conversion view of their
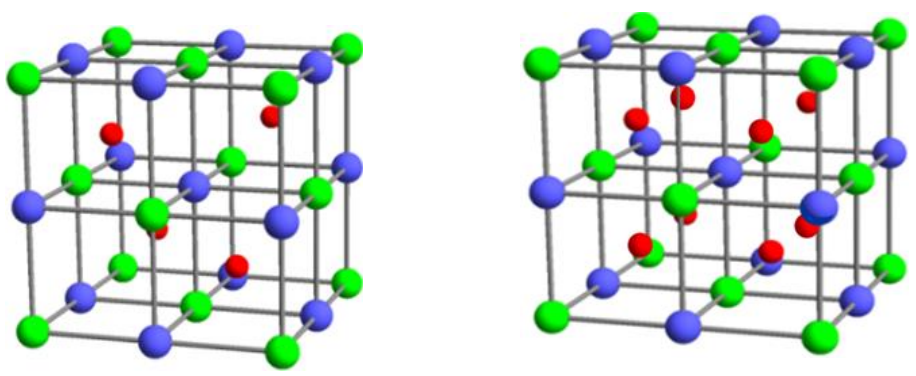

Figure 1. Unit cells of half-Heusler compound (left) and full-Heusler compound (right). Symbols: $\mathrm{X}(\bullet), \mathrm{Y}(\bullet)$, and $\mathrm{Z}(\bullet)$. Starting from the XY zinc blend structure, HH compound can be described as a "half-stuffed zinc blend" and FH compound a "fully-stuffed zinc blend".

high Seebeck coefficient, moderate electrical resistivity, and high thermal stability ${ }^{20,21,22,23,24,25}$. The main disadvantage of these materials is their relatively high lattice thermal conductivity. Nevertheless, as demonstrated by many groups, atomic mass and atomic size fluctuations and various kinds of defects due to alloying could enhance phonon scattering, resulting in reduction of lattice thermal conductivity. Another advantage of $\mathrm{HH}$ compound is that each of the three sublattices can be independently doped. Thus, ideally the power factor and thermal conductivity can be tuned separately. In view of the various material advantages mentioned, it is not surprising that half-Heusler compounds have emerged as one of the most studied TE materials in recent years $^{26,27,28}$.

\subsection{State-of-the-art thermoelectric materials in the mid-to-high temperature range}

ZT versus $T$ plots for various thermoelectric materials can be found in several review articles referenced herein. In view of recent progress made on half-Heusler compounds and their potential roles in mid-to-high temperature energy conversion, it is timely to provide an up-to-date comparison of these materials with other state-of-the-art high ZT compounds, particularly chalcogenides and skutterudites. The plots in Figure 2 are made following the format of figure 6 in reference 29. The competitiveness of half-Heusler compounds, in terms of thermoelectric performance and materials stability and scalability, will undoubtedly continue to generate a plethora of research activities due to the need for practical TE materials. 


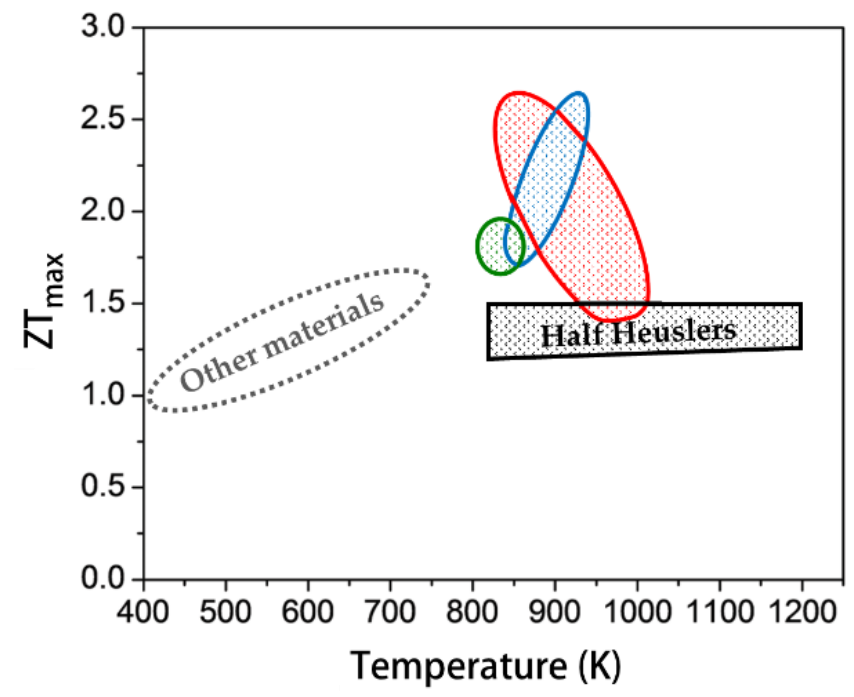

Figure 2. Highest $\mathrm{ZT}\left(\mathrm{ZT}_{\max }\right)$ and temperature at which $\mathrm{ZT}_{\max }$ occurs is shown for four state-of-the-art mid-tohigh temperature thermoelectric compounds: $\mathrm{Cu}$-based chalcogenides (red), skutterudites (green), Sn- and $\mathrm{Pb}$ based chalcogenides (blue), and halfHeuslers (black). The half-Heuslers in the shaded region are those of Gen-3 HH materials presented in Section 5.2.

\subsection{Thermoelectric conversion efficiency}

In its simplest form, the ideal maximum conversion efficiency $\eta$ for a thermoelectric device or generator (TEG) is given by the following expression ${ }^{27}$

$$
\eta=\left(\frac{\mathrm{T}_{\mathrm{h}}-\mathrm{T}_{\mathrm{c}}}{\mathrm{T}_{\mathrm{h}}}\right)\left(\frac{\sqrt{1+\overline{\mathrm{ZT}}}-1}{\sqrt{1+\overline{\mathrm{ZT}}}+\frac{\mathrm{T}_{\mathrm{c}}}{\mathrm{T}_{\mathrm{h}}}}\right)
$$

where the first term in parenthesis on the right is the Carnot efficiency, $\mathrm{T}_{\mathrm{h}}$ is the hot-side temperature, $\mathrm{T}_{\mathrm{c}}$ is the cold-side temperature, and $\overline{\mathrm{ZT}}$ is the temperature-averaged $\mathrm{ZT}$. In reality, $\eta(T)$ is determined by the temperature-dependent TE parameters and not by the average ZT. The relevant equations for calculating $\eta(T)$, which can be found in ref. 30, are highlighted in Figure 3. If the n-leg and p-leg have the same ZT, our expression for $\eta$ converges to the results of Kim et $a l^{31}$. In the absence of unusual temperature dependence, the $\eta$ values calculated using equation (4) and those shown in Figure 1 differ only by a few percent.

The ideal TE conversion efficiencies calculated for several representative state-of-the-art thermoelectric materials are plotted in Figure 4. The few points plotted represent the highest $\eta(T)$ values for these TE materials based on the ZT data obtained from the numerous sources cited in ref. $27 \mathrm{xx}$ (see Figure 2 and caption shown therein) and ref. $26 \mathrm{xx}$ (see Table 1 shown therein), as well as most recent results for high ZT half-Heuslers discussed in Sections 5.2 and 5.3. The TE data for $\alpha-\mathrm{MgSbAg}$ can be found in Ref. 32. xx From the plot, the half-Heusler compounds are seen to have high conversion efficiency comparable to those of chalcognides and skutterudites. Despite the recent advancement in ZT, the present TEG conversion efficiencies lag behind those of a Rankine steam engine or Stirling gas engine. There are areas of waste heat recovery where research and applications of thermoelectric conversion technologies are still active. The interested reader is encouraged to read the commentary by Vining ${ }^{33}$. 


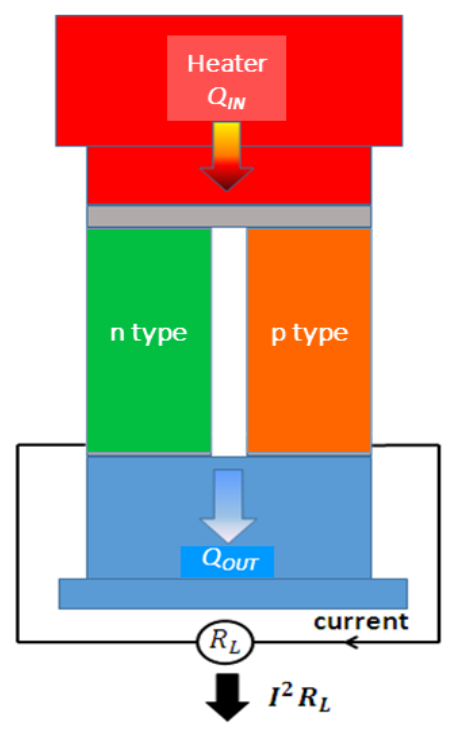

$$
\begin{aligned}
& \eta=\frac{\text { output power }}{\text { heat input to the generator }} \\
& \eta \text { is maximum conversion efficiency obtained by optimizing load } \\
& \text { resistance } R_{L} \text { and ratio of base areas of } \mathrm{n} \text { and } \mathrm{p} \text { legs } \\
& \eta=\frac{\Delta T}{T_{h}} * \frac{\left(1+\Delta T *\left(\frac{\bar{S}}{\left.\left.\left(\overline{\rho_{n}} * \overline{k_{n}}\right)^{\frac{1}{2}}+\left(\overline{\rho_{p}} * \overline{k_{p}}\right)^{\frac{1}{2}}\right)^{2}\left(\frac{S_{h} * T_{h}}{\bar{S} * \Delta T}-\frac{1}{2}\right)\right)^{\frac{1}{2}}-1}\right.\right.}{\frac{S_{h}}{\bar{S}}\left(\left(1+\Delta T *\left(\frac{\bar{S}}{\left(\overline{\rho_{n}} * \overline{k_{n}}\right)^{2}+\left(\overline{\rho_{p}} * \overline{k_{p}}\right)^{1}}\right)^{2}\left(\frac{S_{h} * T_{h}}{\bar{S} * \Delta T}-\frac{1}{2}\right)\right)^{\frac{1}{2}}+1\right)-\frac{\Delta T}{T_{h}}} \\
& \Delta T=T_{h}-T_{C} \\
& \bar{S}=\frac{1}{\Delta T} \int_{T_{c}}^{T_{h}}\left(S_{p}(T)-S_{n}(T)\right) d T \quad S_{h}=\text { Seebeck coefficient at } T_{h} \\
& \overline{k_{n}}=\frac{1}{\left(T_{h}-T_{c}\right)} \int_{T_{c}}^{T_{h}}\left(k_{n}(T)\right) d T \quad \overline{k_{p}}=\frac{1}{\left(T_{h}-T_{c}\right)} \int_{T_{c}}^{T_{h}}\left(k_{p}(T)\right) d T \\
& \overline{\rho_{n}}=\frac{1}{\left(T_{h}-T_{c}\right)} \int_{T_{c}}^{T_{h}}\left(\rho_{n}(T)\right) d T \quad \overline{\rho_{p}}=\frac{1}{\left(T_{h}-T_{c}\right)} \int_{T_{c}}^{T_{h}}\left(\rho_{p}(T)\right) d T
\end{aligned}
$$

Figure 3. (Left) Schematic sketch of a thermoelectric n-p module. The symbols are selfexplanatory. (Right) Equations for computing the maximum conversion efficiency. $S_{h}$ is Seebeck coefficient at the hot end. Thermal conductivity is labeled $k$ following reference 30 .

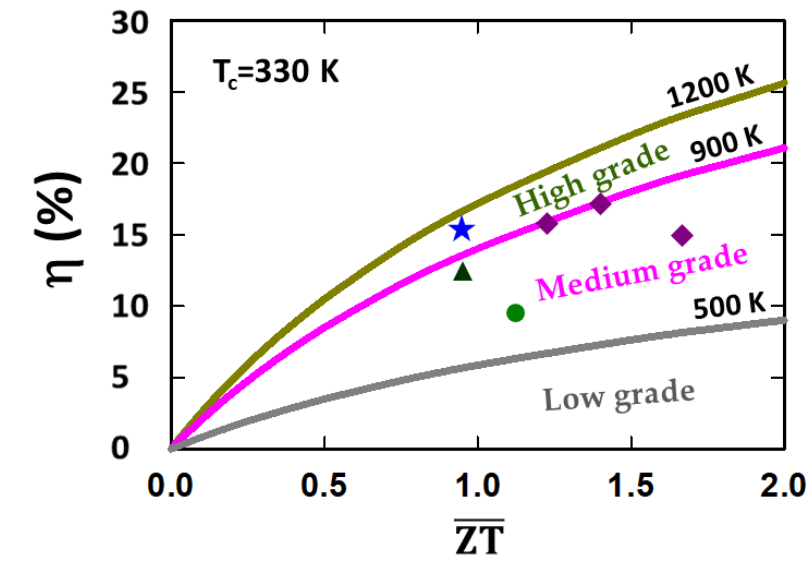

Figure 4. $\eta$ (in percent) versus $\overline{\mathrm{ZT}}$ plots obtained using equation (3). The cool-side temperature $\mathrm{T}_{\mathrm{c}}$ is set at $57^{\circ} \mathrm{C} / 330 \mathrm{~K}$. The three isotherms shown approximately partition the three temperature ranges of waste heat sources mentioned in Section 1. The corresponding Carnot efficiencies at 500,900 , and $1200 \mathrm{~K}$ are 34,63 , and $72 \%$, respectively. $\eta$ for several state-of-the-art compounds with highest $\overline{\mathrm{ZT}}$ are plotted. These compounds include $\mathrm{Pb}$-, $\mathrm{Sn}-$, and $\mathrm{Cu}$-based chalcogenides (solid diamond), half-Heuslers (solid star), skutterudites (solid triangle), and $\alpha-\mathrm{MgSbAg}$ (filled circle) with peak ZT 2.3-2.7, 1.5, and 1.4, respectively. The corresponding $\overline{\mathrm{ZT}}$ are $\sim 1.25-1.7,0.94,0.97$, and 1.1 , respectively. 


\section{Half-Heusler Compounds}

\subsection{Electronic structure}

The electronic structure and structural stability of half-Heusler compounds have been discussed quite extensively in the literature over the last two decades. Several recent papers on high-throughput screening of stable $\mathrm{HH}$ and $\mathrm{FH}$ compositions are recommended for reading ${ }^{13,14}$, $15,16,18$. A half-Heusler compound is semiconducting when the electron valence count (VEC) is 8 (e.g. $\mathrm{LiMgP}^{34}$, bandgap $2.4 \mathrm{eV}$ ) or 18 (e.g HfNiSn ${ }^{9}$ and $\mathrm{TiCoSb}^{35,36}$, bandgap $\sim 0.5$ and $0.9 \mathrm{eV}$, respectively) Those with VEC away from 8 and 18 are metallic. Band structure calculations using FLAPW (full linearized augmented plane wave method) ${ }^{25}$ and LMTO-ASA (linearized muffin tin orbitals - atomic sphere approximation $)^{37}$ showed that hybridization between the d orbitals of $\mathrm{Zr}$ and $\mathrm{Ni}$ led to the formation of the bandgap (d-d gap). Moreover, the electronic bands of $\mathrm{ZrNiSn}$ directly below the gap have strong Ni-d character, while those above the gap are of primarily $\mathrm{Zr}$ d character. Sn-p levels contribute little to the density of states (DOS) in the vicinity of the band gap, indicating that doping that site would merely result in increasing or decreasing the valence electron count without otherwise modifying the band structure near the Fermi level EF. Below the gap lies four $\mathrm{Sn} / \mathrm{Sb} \mathrm{s}$ and $\mathrm{p}$ bands and five bands of predominantly Ni- or Co-d character. When $\mathrm{VEC}=18$, the nine bands are filled and all the bonding states are then occupied while all antibonding or non-bonding states are empty ${ }^{38}$, giving rise to semiconducting behavior. The role of atomic d-state level in bandgap structure was validated by electrical transport measurement ${ }^{39}$, 40. The measurements suggested that introduction of transition metal dopants resulted in the formation of dopant bands within the gap in positions depending on the valance d-shell filling of the dopant atomic species. The observed trend can be understood in terms of the energy level trend of the $\mathrm{d}$ states in the dopant elements ${ }^{39,41}$. It is worth mentioning that bandgap formation in halfmetallic half-Heuslers with VEC >18, an important class of spintronic materials, have also been studied quite extensively. The total spin moments (M) in HH half-metals followed a Slater-Pauling behavior encapsulated in the equation $\mathrm{M}=\mathrm{VEC}-18^{15,17,42}$.

Transition metal and refractory metal based half-Heusler semiconducting compounds have bandgap in the range of a few tenths of eV, or several times $1000 \mathrm{~K}$ on the thermal scale. The bandgap size is most suited for thermoelectric applications in the mid-to-high temperature range. Together with the various material advantages mentioned, namely high power factor, good thermal stability, and demonstrated scalability, it has invigorated the study of half-Heusler compounds for mid-to-high temperature thermoelectric conversion ${ }^{26,27,28}$.

\subsection{Synthesis methods}

The various methods for synthesizing half-Heusler compounds have been highlighted in two recent review articles ${ }^{43,}{ }^{44}$. Many of the half-Heusler compounds studied, particularly those that contained refractory metals with high melting points, were usually produced in the form of ingots using one of the high temperature alloying methods. The latter methods include arc melting, induction melting, and levitation melting. In addition, optical floating zone method and microwave heating have also been used to synthesize HH compounds. The ingots produced from arc melting and induction melting usually contained secondary phases in addition to the $\mathrm{HH}$ phase. The samples were typically annealed at $\sim 650-850^{\circ} \mathrm{C}$ for $7-10$ days to produce single-phase samples ${ }^{20}$, 
$21,22,45,46$. On the other hand, single-phase ingots could be synthesized using levitation melting ${ }^{47}$, 48. The samples produced from the methods mentioned inevitably showed various degrees of porosity. Starting in 2005- 2006, several groups in Japan began to utilize spark plasma sintering (SPS) technique to produce $\mathrm{HH}$ samples for thermoelectric measurement ${ }^{49,50,51}$. In comparison with as-cast samples, the SPSed samples were essentially free of porosity and therefore more robust mechanically. Incidentally, it was one of these groups that first reported a high ZT of $\sim 1.5$ at 700K in some SPSed n-type (Hf,Zr)TiNiSn samples ${ }^{51}$.

The composition of $\mathrm{HH}$ compounds must be carefully determined in order optimize TE properties. Especially in the case of minor alloying such as doping, a small change in the composition can have a drastic effect on the results. Thus, one must be able to control the alloy composition with considerable precision. The dopant content reported so far was at most a few atomic percent or less. As an example, for Sb and V doped (Hf,Zr)NiSn compounds, the author's laboratory first made the $\mathrm{Sn}_{90} \mathrm{Sb}_{10}$ or $\mathrm{Hf}_{90} \mathrm{~V}_{10}$ precursor ingot. A small amount of extra $\mathrm{Sb}$ was added in order to compensate for some loss of $\mathrm{Sb}$ due to evaporation ${ }^{52}$. The HH ingot was then produced by arc melting proper amounts of elemental $\mathrm{Hf}, \mathrm{Zr}, \mathrm{Ni}, \mathrm{Sn}$ and chunks cut from the premelted Sn-Sb or Hf-V ingot. The composition and compositional homogeneity were ascertained by Energy-dispersive spectroscopy (EDS) measurement ${ }^{52,53}$.

\subsection{Initial studies of thermoelectric properties}

As mentioned, half-Heusler compounds began to gain attention of thermoelectric researchers in the late 1990s. Earlier, Cook et $\mathrm{al}^{7}$ reported a power factor of $\sim 2.1 \mathrm{~W} / \mathrm{m}-\mathrm{K}$ at $750 \mathrm{~K}$ in as-grown TiNiSn samples. Although the high thermal conductivity of TiNiSn resulted in ZT of only $0.3^{22}$, the potential of half-Heusler compounds as thermoelectric materials was duly recognized. The studies that followed were focused on the dopability of these compounds and the effectiveness of the dopants, as well as the effect of alloying on thermal conductivity ${ }^{20,21,22,23,24}$. Most of the measurements were conducted up to $300 \mathrm{~K}$. The results from these studies were discussed in a review article by the present author ${ }^{46}$. Large Seebeck coefficients approximately in the range of $100-400 \mu \mathrm{V} / \mathrm{K}$ (i.e. in magnitude) and thermal conductivity approximately in the range of 3-20 $\mathrm{W} / \mathrm{m}-\mathrm{K}$ were reported by various groups in a variety of $\mathrm{HH}$ compositions. The highest roomtemperature power factor (PF) for the undoped compounds was measured on TiNiSn $(0.22 \mathrm{~W} / \mathrm{m}$ $\mathrm{K})^{22}$ and $\mathrm{ErNiSb}(0.26 \mathrm{~W} / \mathrm{m}-\mathrm{K})^{54}$, while the lowest thermal conductivity $(\kappa)$ was found in $(\mathrm{Zr}, \mathrm{Hf})(\mathrm{Co}, \mathrm{Pt})(\mathrm{Sn}, \mathrm{Sb})(3.1 \mathrm{~W} / \mathrm{m}-\mathrm{K})^{55}$ and $\mathrm{TmNiSb}(2.8 \mathrm{~W} / \mathrm{m}-\mathrm{K})^{54}$. The transition metal based $\mathrm{HH}$ compounds studied tended to show opposite trends in PF and $\kappa$, that is, those that had higher PF tended to have higher $\kappa$ and vice versa. Doping was employed to enhance PF without increasing $\kappa$ at high temperature. A high power factor of $3.85 \mathrm{~W} / \mathrm{m}-\mathrm{K}$ as well as ZT of 0.45 was obtained in $\left(\mathrm{Ti}_{0.5} \mathrm{Hf}_{0.5}\right) \mathrm{Ni}\left(\mathrm{Sn}_{0.975} \mathrm{Sb}_{0.025}\right)$ at $700 \mathrm{~K}^{46}$.

\subsection{First generation (Gen-1) thermoelectric half-Heusler materials}

As mentioned in Section 1, the layout of this article is organized according to the three generations (abbreviated Gen-1, Gen-2, Gen-3) of TE half-Heusler materials. A high-level summary of these materials is shown in Table 1 . In this section, we will highlight some of the 
high-performance Gen-1 half-Heusler materials reported in the 2000's. Gen-2 and Gen-3 HH materials will be featured in Section 4 and Section 5, respectively. Among Gen-1 HH materials,

Table 1. Chronological classification of half-Heusler compounds (interchangeable with materials to include composites) based on advances in synthesis methods and technical approaches as well as increase in ZT. ZT values are cited in the text. The widely adopted term "spark plasma sintering" is used herein even though "current-assisted sintering" is technically more accurate. The dawn of the Gen-3 era, approximately, overlapped with the publication of two review articles on thermoelectric $\mathrm{HH}$ compounds ${ }^{44,} 44$.

\begin{tabular}{|c|c|c|c|c|}
\hline $\begin{array}{c}\text { HH materials } \\
\text { classification }\end{array}$ & Synthesis & $\begin{array}{c}\text { Technical } \\
\text { approaches }\end{array}$ & $\begin{array}{c}\text { Highest } \\
\text { ZT }\end{array}$ \\
\hline $\begin{array}{c}\text { Gen-1 } \\
(2000 \text { 's) }\end{array}$ & $\begin{array}{c}\text { almost exclusively } \\
\text { melting and } \\
\text { annealing }\end{array}$ & $\begin{array}{c}\text { alloying, } \\
\text { doping }\end{array}$ & $\begin{array}{c}\text { alloy scattering lowers } \\
\kappa_{\mathrm{L}}, \text { doping optimizes PF }\end{array}$ & $\begin{array}{c}0.85(\mathrm{n}) \\
0.5(\mathrm{p})\end{array}$ \\
\hline $\begin{array}{c}\text { Gen-2 } \\
\text { (late 2000's to } \\
\text { early 2010's) }\end{array}$ & $\begin{array}{c}\text { widely adopted } \\
\text { spark plasma } \\
\text { sintering and hot } \\
\text { pressing }\end{array}$ & $\begin{array}{c}\text { sample } \\
\text { densification, } \\
\text { nanostructuring }\end{array}$ & $\begin{array}{c}\text { robust samples, grain } \\
\text { refinement reduces } \kappa_{\mathrm{L}}, \\
\text { enhancing S }\end{array}$ & $\sim 1$ \\
\hline $\begin{array}{c}\text { Gen-3 } \\
\text { (post early } \\
2010 \text { 's) }\end{array}$ & $\begin{array}{c}\text { combination of } \\
\text { mentioned methods }\end{array}$ & $\begin{array}{c}\text { phase separation, } \\
\text { structure ordering, } \\
\text { band engineering }\end{array}$ & $\begin{array}{c}\text { additional mechanisms } \\
\text { (see section 5.2) }\end{array}$ & $\sim 1.5$ \\
\hline
\end{tabular}

the highest ZT was reported to be $\sim 0.85$ for $\mathrm{n}$-type $\mathrm{Hf}_{0.75} \mathrm{Zr}_{0.25} \mathrm{NiSn}_{0.975} \mathrm{Sb}_{0.025}{ }^{56},{ }^{57}$ and $\sim 0.5$ for $\mathrm{p}$ type $\mathrm{Zr}_{0.5} \mathrm{Hf}_{0.5} \mathrm{CoSb}_{0.8} \mathrm{Sn}_{0.2}{ }^{58}$, both occurring at $1000 \mathrm{~K}$. The higher $\mathrm{ZT}$ compared with those of unalloyed ternary $\mathrm{HH}$ compounds was achieved through alloy substitution that increased phonon scattering and power factor, as well as by doping that enhanced the power factor. Earlier, an international team obtained $\mathrm{ZT} \sim 0.7$ at $800 \mathrm{~K}$ for $\mathrm{Zr}_{0.5} \mathrm{Hf}_{0.5} \mathrm{Ni}_{0.8} \mathrm{Pd}_{0.2} \mathrm{Sn}_{0.99} \mathrm{Sb}_{0.01}$ synthesized using SPS before the latter synthesis technique was widely adopted in the US ${ }^{59}$. Besides the beneficial effect of doping mentioned above, mass fluctuations and strain field fluctuations due to differences in atomic sizes and interatomic force couplings resulted in point defect scattering that significantly reduced $\kappa^{60}$. Most recently, Liu et $\mathrm{al}^{61}$ ascribed their measurement of $\mathrm{ZT} \sim 1$ in $\mathrm{Nb}$-doped ( $\mathrm{Zr}, \mathrm{Hf}) \mathrm{CoSb}$ compounds to the mass fluctuation and "lanthanide contraction" effects. Lanthanide contraction resulted in the small atomic size difference between $\mathrm{Zr}$ and $\mathrm{Hf}$. The similar atomic size ensured a relatively uniform atomic potential profile, and therefore did not affect the carrier mobility. Meanwhile, the difference between atomic mass of $\mathrm{Zr}$ and $\mathrm{Hf}$ gives rise to mass fluctuation, suppressing the thermal conductivity.

\section{Nanostructured Half-Heusler Materials}

\subsection{Microstructural features}


There are principally two types of nanostructured half-Heusler materials, namely: (i) nanobulk materials composed nearly entirely of nano-size grains, and (ii) composite materials that contain submicron or micron size particles or domains. Domains are usually associated with phase separation. As discussed extensively in the review article by Xie et al ${ }^{43}$, and Chen and Ren ${ }^{44}$ and references therein, nano-bulk HH materials were fabricated by consolidating micron-size particles consisting of nano-size grains using spark plasma sintering or hot pressing. The latter thermomechanical processes gave better control of the microstructure through grain growth or grain refinement, and thus were suitable for producing nano-bulk materials. The process usually occurred at $\sim 80 \%$ of the melting temperature under an applied pressure of 50-1000 MPa. The powder particles were produced either by mechanical alloying of elemental powders, melt spinning of molten alloy, or mechanical attrition of the pulverized alloy ingot. As reviewed by Xie et al, nanocomposites were formed either via in-situ growth or ex-situ addition. Figure 5 shows the sketches of three kinds of composite microstructures.

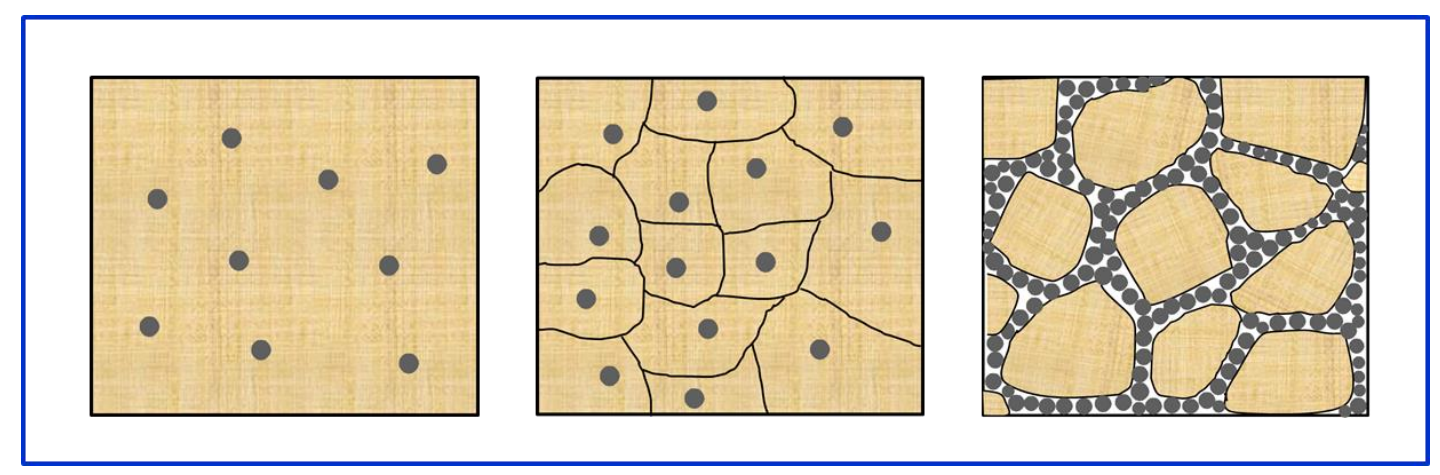

Figure 5. Left panel: Nanoparticles in monocrystalline host. Middle panel: Nanoparticles in polygrained host. Right panel: Nanoparticles aggregated at grain boundaries. The composites studied usually contain different sizes of particles or domains that are more efficient at scattering phonons. A nano-bulk phase is formed when the sample volume is filled with nanoparticles.

Spontaneous growth of nano-bulk $\mathrm{HH}$ materials via recrystallization - Mechanical milling has been commonly utilized to produce half-Heusler nanograins with size less than $100 \mathrm{~nm}$. The nano-size grain structure was found to be retained in nano-bulk half-Heusler samples produced by

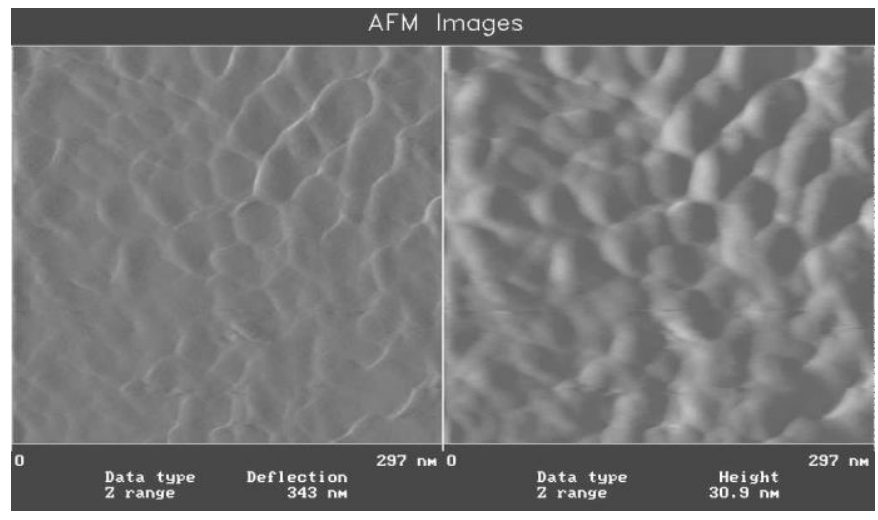

Figure 6. AFM images obtained in the deflection mode (left) and height mode (right) on shock-consolidated TiNiSn(Sb) powder compact (Image: $297 \mathrm{~nm}$ x 297nm). Preparation of alloy powders: ingot was preannealed at $900^{\circ} \mathrm{C}$ for 14 hours prior to ball milling. 
shock compaction ${ }^{62}$. The nano-bulk structure was confirmed by atomic force microscopy (AFM) study. Figure 6 shows the AFM micrographs. The average grain size was calculated to be $\sim 35 \mathrm{~nm}$ with a standard deviation of $\sim 6 \mathrm{~nm}$. On the other hand, SPS and hot pressing of ball-milled powders often resulted in grain growth in the grain size increasing to $\sim 100-400 \mathrm{~nm}^{63,64}$. Recently, it was reported that the nano-bulk state could also be realized via a recrystallization process ${ }^{53}$. This was observed in some SPSed $\mathrm{Hf}_{0.6} \mathrm{Zr}_{0.4} \mathrm{NiSn}_{0.995} \mathrm{Sb}_{0.005}$ nano-bulk samples. The original arc-melted ingot contained micron-size (Hf,Zr) $\mathrm{Ni}_{2} \mathrm{Sn}$ full-Heusler phase and two $\mathrm{HfZr}$ intermetallic phases with $\mathrm{Ni}$ and $\mathrm{Sn}$, respectively, in addition to the $\mathrm{HH}$ phase. The ingot was pulverized prior to compaction by SPS. After SPS, a single-phase nano-bulk sample was obtained with grain size in the range 50-200 $\mathrm{nm}$. Recrystallization apparently occurred during the transformation from the mixed phase state to single phase state that led to the nano-bulk state. The microstructures of the investigated $\mathrm{Hf}_{0.6} \mathrm{Zr}_{0.4} \mathrm{NiSn}_{0.995} \mathrm{Sb}_{0.005}$ samples in the arc-melted and annealed, SPSed, and postSPS annealed states are shown in Figure 7.
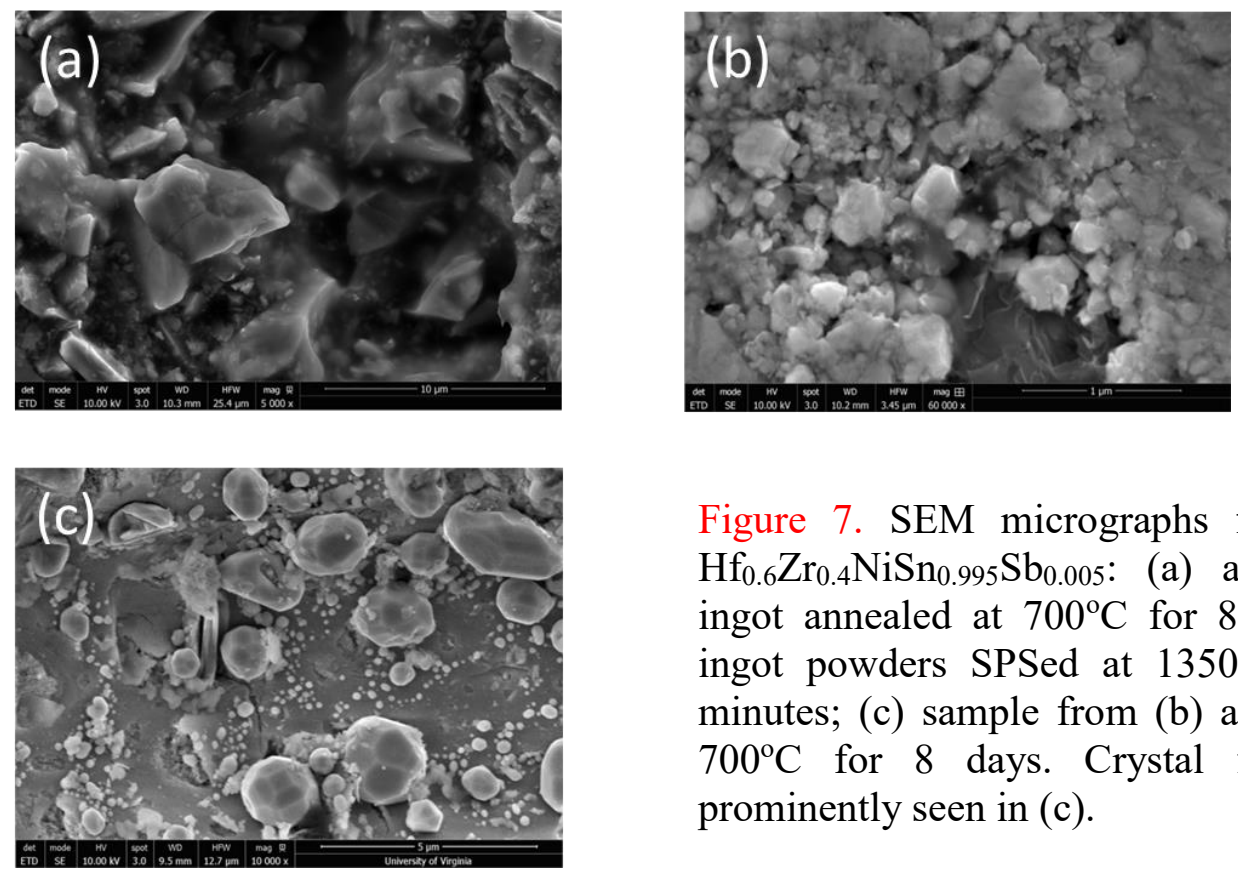

Figure 7. SEM micrographs for n-type $\mathrm{Hf}_{0.6} \mathrm{Zr}_{0.4} \mathrm{NiSn}_{0.995} \mathrm{Sb}_{0.005}$ : (a) arc melted ingot annealed at $700^{\circ} \mathrm{C}$ for 8 days; (b) ingot powders SPSed at $1350^{\circ} \mathrm{C}$ for 30 minutes; (c) sample from (b) annealed at $700^{\circ} \mathrm{C}$ for 8 days. Crystal facets are prominently seen in (c).

Nano- and micro-structures from phase separation - In-situ formation of nanostructured $\mathrm{HH}$ composites occurred in directional grown $\mathrm{Ti}_{0.37} \mathrm{Zr}_{0.37} \mathrm{Hf}_{0.26} \mathrm{NiSn}^{65}$, annealed ingot of $\mathrm{Ti}_{0.5} \mathrm{Hf}_{0.5} \mathrm{CoSb}_{0.8} \mathrm{Sn}_{0.2}{ }^{66}$, and annealed cold-pressed ${ }^{67}$ and $\mathrm{SPSed}^{68} \mathrm{Ti}_{0.5} \mathrm{Zr}_{0.25} \mathrm{Hf}_{0.25} \mathrm{NiSn}$ powders. The obtained samples showed a two-phase microstructure characterized by nano-micro scale Tirich and Hf-rich regions in the matrix. It is evident that (Ti,Hf,Zr)-based $\mathrm{HH}$ compounds are prone to phase separation, which is likely due to the smaller atomic size of Ti compared with $\mathrm{Hf}$ and $\mathrm{Zr}$. The hetereogeneous microstructure in phase-separated materials enhanced phonon scattering, reducing the lattice thermal conductivity, which led to high ZT in some Gen-2 HH materials (Table 2). On the other hand, phase separation was also reported for (Hf,Zr)NiSn using high-resolution synchrotron radiation powder $\mathrm{x}$-ray diffraction ${ }^{69}$. In addition to experimental studies, phase separation in (Ti,Zr,Hf)-based $\mathrm{HH}$ alloys was also confirmed in combined ab initio/Calphad computation of binodal and spinodal isopleths for quaternary (Ti,Hf)NiSn and (Ti,Zr)NiSn by 
Gurth and Rogl et $\mathrm{al}^{70}$. The latter authors pointed out that binodal and spinodal decompositions could be avoided by sintering/annealing the samples at above the critical temperatures. Separately, Berche et al performed ab initio calculation that also revealed phase separation in the ( $\mathrm{Ti}, \mathrm{Zr}, \mathrm{Hf}$ )based $\mathrm{HH}$ alloys in agreement with Calphad results ${ }^{71}$. An important message from the studies mentioned is that one may design heat treatment protocol to control the microstructure in (Ti,Zr,Hf)-based HH compounds as a practical approach to improving thermoelectric properties.

\subsection{Second generation (Gen-2) half-Heusler materials, ZT 1.}

Since 2010, the popular utilization of thermo-mechanical processing methods based on spark plasma sintering and hot pressing to synthesize dense samples (higher than $95 \%$ of the theoretical density) have led to ZT near 1, or higher, for both n-type and p-type half-Heusler materials ${ }^{43,44}$. It should be pointed out that ZT near 1 was also reported for samples synthesized using conventional growth technique ${ }^{65,66}$. The peak ZT in n-type and p-type compounds tended to occur in the temperature regions of $700-900 \mathrm{~K}$ and $950-1050 \mathrm{~K}$, respectively. The improvement of TE properties and associated ZT were ascribed to enhanced scattering of charge carriers and phonons due to presence of nano- and micro-scale structures ${ }^{63,64,72,73,74,75,76,77,78,79}$ produced by the various nanostructuring methods mentioned in the previous Section. On the other hand, the enhancement can also be attributed to grain refinement ${ }^{47}$,Error! Bookmark not defined. or phase separation as revealed in microscopy studies ${ }^{65}$. Thus, ZT enhancement can also occur without the need for ball milling or melt spinning. Grain refinement in SPSed samples, as discussed in the previous section, deserves further investigation. Besides ball milling, hierarchical microstructure, which could exist in the heterogeneous samples mentioned, is ideal for scattering both short and long wavelength phonons in reducing lattice thermal conductivity ${ }^{73,80,81}$. Charge carriers can also be

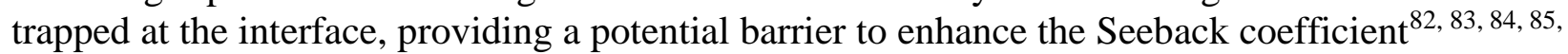
86, 87. Such enhancements were observed in nanostructured half-Heusler materials ${ }^{63,72,88,89,90 .}$ Some examples are shown in Figure 8. The synthesis methods employed to produce Gen-2 materials and their microstructural features are highlighted in Table 2.
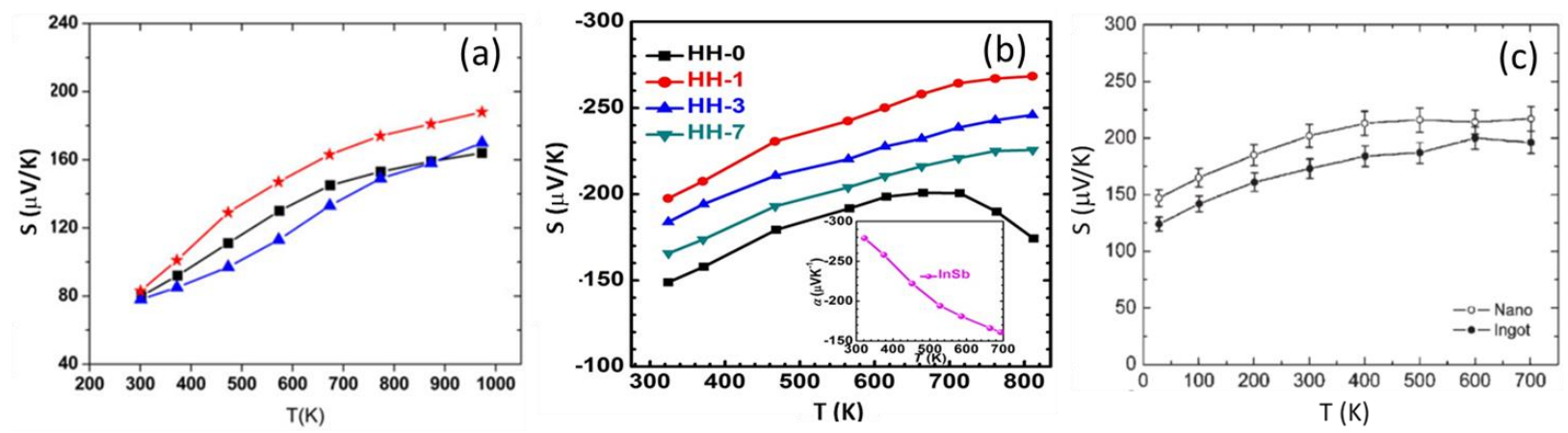

Figure 8. Thermopower enhancement in nanostructured half-Heusler materials: (a) $\mathrm{Hf}_{0.3} \mathrm{Zr}_{0.7} \mathrm{CoSn}_{0.3} \mathrm{Sb}_{0.7}$ dispersed with 0 (square), 1 (triangle), and 2 vol. \% (star) $\mathrm{ZrO}_{2}$ nanoparticles (ref. 72); (b) $\mathrm{Ti}_{0.5} \mathrm{Zr}_{0.25} \mathrm{Hf}_{0.25} \mathrm{Co}_{0.95} \mathrm{Ni}_{0.05} \mathrm{Sb}$ with $0,1,3$ and 7 at. \% of InSb nanoinclusions (ref. 88); (c) $\mathrm{Zr}_{0.5} \mathrm{Hf}_{0.5} \mathrm{CoSb}_{0.8} \mathrm{Sn}_{0.2}$ nano-bulk and ingot samples (ref. 63). Improvement in $\mathrm{ZT}$ of these three systems comes from the simultaneous increase in $\mathrm{S}$ and decrease in $\kappa$. 
Table 2. Listed are representative Gen-2 half-Heusler materials (both n-type and p-type) with ZT 1, methods of synthesis, and microstructural features. Abbreviations: Ball milling (BM), hot press (HP), spark plasma sintering (SPS), arc melting (AM), levitation melting (LM), and melt spinning (MS).

\begin{tabular}{|c|c|c|c|c|}
\hline $\begin{array}{l}\text { Representative } \\
\text { HH materials }\end{array}$ & Synthesis methods & $\begin{array}{l}\text { Microstructural } \\
\text { features }\end{array}$ & $\begin{array}{l}\text { Type } \\
\text { (n or } p \text { ) }\end{array}$ & Refs. \\
\hline$(\mathrm{Hf}, \mathrm{Zr}, \mathrm{Ti}) \mathrm{Co}(\mathrm{Sb}, \mathrm{Sn})$ & $\mathrm{BM}$ and $\mathrm{HP}$ & nanograined structure & $\mathrm{p}$ & 74 \\
\hline Sb-doped (Hf,Zr,Ti)NiSn & $\mathrm{BM}$ and $\mathrm{HP}$ & nanograined structure & $\mathrm{n}$ & 75 \\
\hline$(\mathrm{Ti}, \mathrm{Zr}, \mathrm{Hf}) \mathrm{NiSn}$ & Directional growth & phase separation & $\mathrm{n}$ & 65 \\
\hline$(\mathrm{Ti}, \mathrm{Zr}, \mathrm{Hf}) \mathrm{Co}(\mathrm{Sb}, \mathrm{Sn})$ & AM and annealed & $\begin{array}{c}\text { phase separation } \\
\text { dendrites }\end{array}$ & $\mathrm{p}$ & 66 \\
\hline Sb-doped (Hf,Zr)NiSn & LM and SPS/HP & grain refinement & $\mathrm{n}$ & 47 \\
\hline Sb-doped (Hf,Zr)NiSn & MS and SPS & $\begin{array}{l}\text { nanograins embedded } \\
\text { in submicron grains }\end{array}$ & $\mathrm{n}$ & 73 \\
\hline $\begin{array}{c}(\mathrm{Hf}, \mathrm{Zr}) \mathrm{Co}(\mathrm{Sn}, \mathrm{Sb}) / \\
\text { nano- } \mathrm{ZrO}_{2}\end{array}$ & AM and SPS & embedded nanoparticles & $\mathrm{p}$ & 72 \\
\hline Sb-doped (Hf,Zr)NiSn & AM and SPS & $\begin{array}{l}\text { nano- and micron- } \\
\text { grained structures }\end{array}$ & $\mathrm{n}$ & 72 \\
\hline
\end{tabular}

\subsection{Conversion efficiency of TEG built with Gen-2 half-Heusler materials}

The power conversion efficiency $(\eta)$ of single-couple thermoelectric generator (TEG) built with Gen-2 half-Heusler materials, specially n-type $\mathrm{Hf}_{0.6} \mathrm{Zr}_{0.4} \mathrm{NiSn}_{0.995} \mathrm{Sb}_{0.005}$ and p-type $\mathrm{Hf}_{0.3} \mathrm{Zr}_{0.7} \mathrm{CoSn}_{0.3} \mathrm{Sb}_{0.7} / \mathrm{ZrO}_{2}$, was found to reach $\sim 9 \%$ near $1000 \mathrm{~K}^{72}$. The TEG delivered a power density near $8.9 \mathrm{~W} / \mathrm{cm}^{2}$, decreasing to $\sim 3.5 \mathrm{~W} / \mathrm{cm}^{2}$ for a 49 -couple TEG (unpublished results). The $\eta$ achieved was near $\eta_{\text {ideal }} \sim 9.2 \%$ using the expressions in Section 2.3. The results are shown in Figure 9. For comparison, typical $\eta$ for commercial TEGs is 5-8\%. Cook et al reported conversion efficiency of $20 \%$ for a three-stage cascade $\mathrm{TEGs}^{91}$. The assembly of the cascade devices included nano-bulk $\mathrm{Bi}_{2} \mathrm{Te}_{3}$ materials on the cold-side bottom stage, PbTe and TAGS (AgSbTe $2-\mathrm{GeTe}$ ) compounds for the middle stage, and half-Heusler materials for the high-temperature top stage. Figure 10 shows the schematic diagram of the cascade device and the conversion efficiencies obtained in several tests of the device performance. The high TE conversion efficiency achieved in Gen-2 HH materials indicated that these materials are promising candidates for mid-to-high temperature waste heat recovery applications. Compared with the half-Heuslers, other prospective TE materials such as skutterudites and $\mathrm{Pb}$-based chalcogenides have issues with poor thermal stability, medium to high toxicity, and weak mechanical strength. 


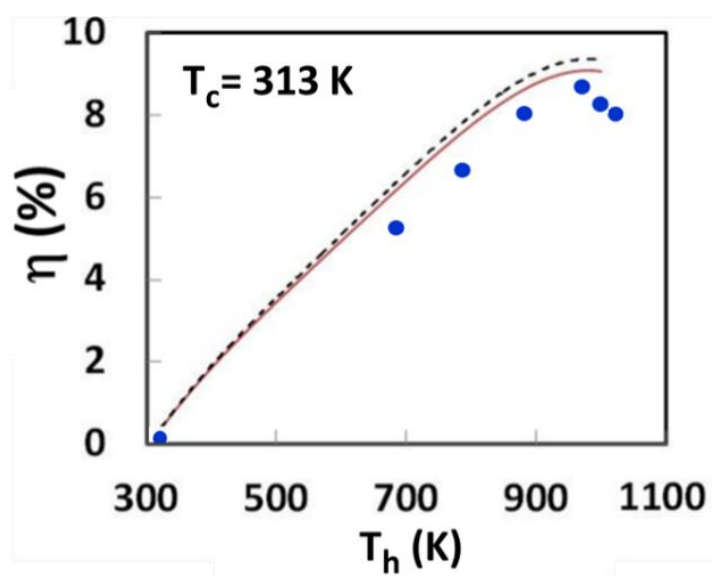

Figure 9. Thermoelectric power conversion efficiency for a n-p couple module built with n-type $\mathrm{Hf}_{0.6} \mathrm{Zr}_{0.4} \mathrm{NiSn}_{0.995} \mathrm{Sb}_{0.005}$ compound and p-type $\mathrm{Hf}_{0.3} \mathrm{Zr}_{0.7} \mathrm{CoSn}_{0.3} \mathrm{Sb}_{0.7} / \mathrm{ZrO}_{2}$ nanocomposite. The plots shown are: experimental data (blue filled circle), calculated results using temperatureaveraged ZT (dashed line), calculated results using temperature-dependent TE properties (solid line) discussed in section 2.4. Figure is adapted from reference 30 with some modification.
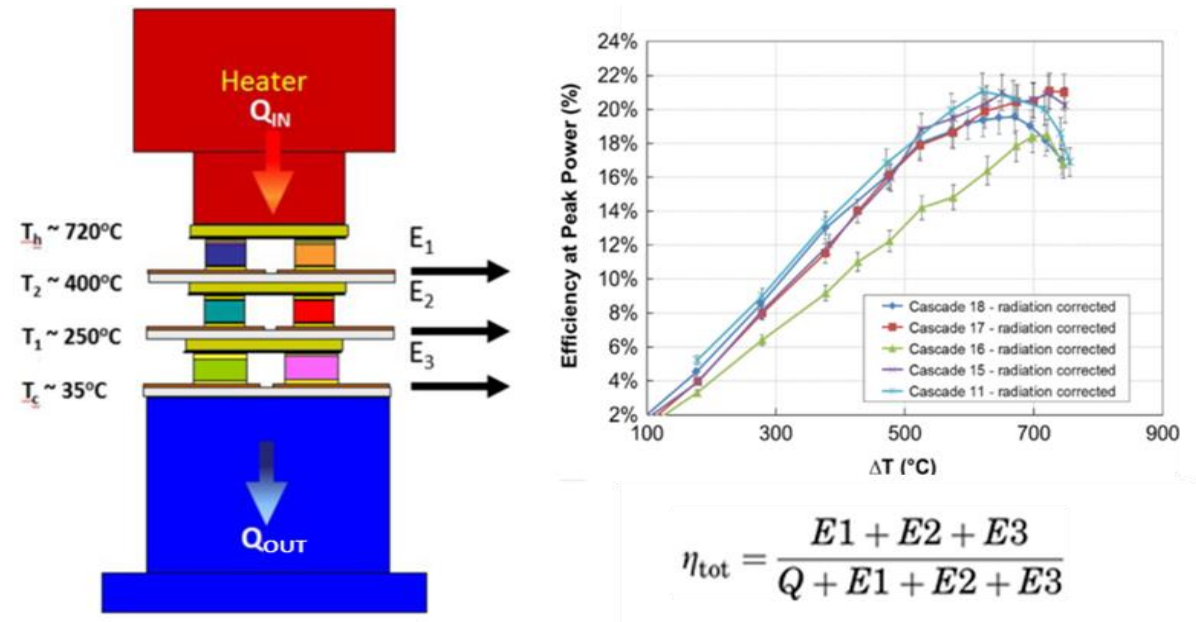

Figure 10. (Left) Schematic of a 3-stage cascade TEG. (Right) Summary of cascade efficiencies obtained in power testing. $\eta_{\text {tot }}$ is the total conversion efficiency of the cascade. The content of the figure is extracted from Ref. 91. The schematic TEG is slightly modified for clarity purpose.

\section{Recent Development of Half-Heusler Materials}

The electronic and vibrational contributions to thermoelectric properties are intertwined (c/o Section 2). Nanostructure influences both thermal conductivity and thermopower. Alloy composition influences both thermal conductivity and band structure. At the fundamental level, 
such complexity appears to suggest a departure from the "phonon glass electron crystal" paradigm. Nonetheless, recent efforts by several groups have succeeded in optimizing the ZT in half-Heusler compounds. In this section, we will focus on the advances made in thermoelectric half-Heusler compounds in the past few years. Two prior review articles ${ }^{43,44}$ on thermoelectric HH compounds have provided us with an excellent account of the state-of-the-art until 2013.

\subsection{Third generation (Gen-3) half-Heusler materials with ZT>1.}

Although nanostructure continued to play an important role in the development of Gen-3 halfHeusler materials, discovery of new $\mathrm{HH}$ compositions has emerged as a promising direction for band engineering in improving TE properties. The various improvements achieved have led to the emergence of third-generation (Gen-3) HH materials with ZT reaching 1.5. The highest ZT reported for several n-type and p-type half-Heusler compounds are summarized in Table 3 . The origins of high ZT were attributed to various factors, namely, microstructure, mass fluctuations, structural order, dopant resonant states, heavy hole band, and high valence band degeneracy, as well as soft phonons. These various approaches to high ZT in HH compounds are referenced in the below section.

Table 3. Gen-3 half-Heusler materials with ZT $>1$. Maximum ZT values occur at the temperatures indicated. Included are enabling factors that lead to beneficial effects on thermoelectric properties. Other features may coexist in a less prominent way.

\begin{tabular}{|c|c|c|c|c|}
\hline \multicolumn{5}{|c|}{ N-Type Half-Heusler Compounds } \\
\hline Materials & $\mathrm{ZT}$ & Enabling recipes & $\begin{array}{l}\text { Beneficial } \\
\text { effects }\end{array}$ & Refs. \\
\hline $\mathrm{Ti}_{0.5} \mathrm{Zr}_{0.25} \mathrm{Hf}_{0.25} \mathrm{NiSn}$ & $\begin{array}{c}1.2 \\
(830 \mathrm{~K})\end{array}$ & Phase separation & Lower $\kappa$ & 67 \\
\hline $\mathrm{Hf}_{0.6} \mathrm{Zr}_{0.4} \mathrm{NiSn}_{0.995} \mathrm{Sb}_{0.005}$ & $\begin{array}{c}1.2 \\
(860 \mathrm{~K})\end{array}$ & Strain reduction & $\begin{array}{c}\text { Higher } \rho \text { and } \mathrm{S} \text {, } \\
\text { lower } \kappa\end{array}$ & 53 \\
\hline $\mathrm{Hf}_{0.65} \mathrm{Zr}_{0.25} \mathrm{Ti}_{0.15} \mathrm{NiSn}_{0.995} \mathrm{Sb}_{0.005}$ & $\begin{array}{c}1.3 \\
(830 \mathrm{~K})\end{array}$ & $\begin{array}{l}\text { Nano-oxide } \\
\text { embedment }\end{array}$ & $\begin{array}{c}\text { Higher } \rho \text { and } \mathrm{S}, \\
\text { lower } \kappa\end{array}$ & 30 \\
\hline $\mathrm{Hf}_{0.59} \mathrm{Zr}_{0.40} \mathrm{~V}_{0.01} \mathrm{NiSn}_{0.995} \mathrm{Sb}_{0.005}$ & $\begin{array}{c}1.3 \\
(900 \mathrm{~K})\end{array}$ & $\begin{array}{l}\text { Dopant } \\
\text { resonant states }\end{array}$ & $\begin{array}{c}\text { Higher } \rho \text { and } \mathrm{S} \text {, } \\
\text { lower } \kappa\end{array}$ & 92 \\
\hline $\begin{array}{c}\mathrm{Ti}_{0.5} \mathrm{Zr}_{0.5} \mathrm{NiSn}_{0.98} \mathrm{Sb}_{0.02} \\
\mathrm{Ti}_{0.5} \mathrm{Zr}_{0.25} \mathrm{Hf}_{0.25} \mathrm{NiSn}_{0.98} \mathrm{Sb}_{0.02}\end{array}$ & $\begin{array}{c}1.2 \\
(820 \mathrm{~K})\end{array}$ & $\begin{array}{l}\text { Presence of } \\
\text { Nanograin }\end{array}$ & $\begin{array}{c}\text { Higher } \rho \text { and } \mathrm{S} \text {, } \\
\text { lower } \kappa\end{array}$ & 70 \\
\hline $\mathrm{Ti}_{0.5} \mathrm{Zr}_{0.25} \mathrm{Hf}_{0.25} \mathrm{NiSn}$ & $\begin{array}{c}1.5 \\
(820 \mathrm{~K})\end{array}$ & $\begin{array}{c}\text { Similar to } \\
\text { Reference [14] }\end{array}$ & $\begin{array}{c}\text { Higher } S, \\
\text { lower } \rho \text { and } \kappa\end{array}$ & 93 \\
\hline
\end{tabular}




\begin{tabular}{|c|c|c|c|c|}
\hline $\begin{array}{c}\mathrm{FeNb}_{0.88} \mathrm{Hf}_{0.12} \mathrm{Sb} \\
\mathrm{FeNb}_{0.86} \mathrm{Hf}_{0.14} \mathrm{Sb}\end{array}$ & $\begin{array}{c}1.5 \\
(1200 \mathrm{~K})\end{array}$ & $\begin{array}{c}\text { Heavy hole band, } \\
\text { high dopant } \\
\text { content, heavy } \\
\text { atomic mass }\end{array}$ & $\begin{array}{c}\text { Lower } \rho, \text { low } \\
\kappa, \text { high } \mathrm{S}\end{array}$ & 94 \\
\hline $\mathrm{ZrCoBi}_{0.65} \mathrm{Sb}_{0.15} \mathrm{Sn}_{0.20}$ & 1.4 & $\begin{array}{c}\text { High hole band } \\
\text { degeneracy, high } \\
\text { dopant content, } \\
\text { low energy phonon }\end{array}$ & $\begin{array}{c}\text { Lower } \rho, \text { low } \\
\kappa, \text { high } \mathrm{S}\end{array}$ & 95 \\
\hline $\mathrm{Ta}_{0.74} \mathrm{~V}_{0.1} \mathrm{Ti}_{0.16} \mathrm{FeSb}$ & 1.52 & $\begin{array}{c}\text { High hole band } \\
\text { degeneracy, low } \\
\text { energy phonon, } \\
\text { point defect }\end{array}$ & $\begin{array}{c}\text { Lower } \rho, \text { low } \\
\kappa, \text { high } \mathrm{S}\end{array}$ & 96 \\
\hline
\end{tabular}

\subsection{Paths to high ZT beyond nanostructuring}

As Table 3 shows, recent development of thermoelectric half-Heusler compounds involved new approaches that led to beneficial electronic and thermal properties. Band engineering has played a definitive role in achieving ZT as high as 1.5. We will highlight these new approaches and their enabling mechanisms below.

(i) Improve bandgap by reducing lattice strain - Antisite disorder involves transfer of $\mathrm{Ni}$ atoms from occupied fcc sublattice to vacant fcc sublattice sites in the HH lattice ${ }^{97}$. Recently, ab initio calculation showed that interstitial defects were also stable in the HH lattice ${ }^{98}$. Structural disorder led to the formation of in-gap states, effectively reducing the size of the bandgap ${ }^{98,99}$. The structural defects reported could also strain the crystal lattice, which would have an effect on the bandstructure. Investigation of TE properties of disordered $\mathrm{HH}$ compounds has recently gained attention $^{53}, 98,100,101,102,103,104,105,106$. The disorder tends to suppress the lattice thermal conductivity, resulting in enhanced ZT. In one of the studies, it was found that the strain in HH compounds could be reduced if the samples were sintered at sufficiently high temperatures just below melting ${ }^{53}$. The $\mathrm{X}$-ray pattern for $\mathrm{Hf}_{0.6} \mathrm{Zr}_{0.4} \mathrm{NiSn}_{0.995} \mathrm{Sb}_{0.005}$ is shown in Figure 11 (a). The inset shows peak widths of the (220) reflection obtained on samples that were synthesized under different conditions. As Figure 11 (b) shows, the strain decreases with increasing synthesis temperature, from samples annealed at $700{ }^{\circ} \mathrm{C}$ to those sintered near the melting point $\left(\sim 1450{ }^{\circ} \mathrm{C}\right)$, by as much as $30 \%$. The effect of strain on thermoelectric properties is notable, as can be seen in the large enhancement in the power-factor temperature product, $\mathrm{PF}^{*} \mathrm{~T}$. The latter increased by nearly $50 \%$ as the synthesis temperature increased from $700^{\circ} \mathrm{C}$ to $1350^{\circ} \mathrm{C}$. The results are shown in Figure 11 (c). This resulted in a 20\% increase in ZT, from 1 to 1.2. The increase in power factor, partly responsible for the increase in ZT, was ascribed to the decrease in carrier density and increase in carrier mobility. There was also a corresponding increase in the size of the bandgap. The mitigation of lattice strain has apparently resulted in the reduction of in-gap defect states. The approach to reduce lattice strain to improve TE properties may also be applicable to other thermoelectric materials. 
(ii) Enhance thermopower with dopant resonant states - Under the right orbital hybridization condition, resonant states manifest as a localized sub-band in the density of states (DoS) near the Fermi level. The enhanced DoS that resulted can lead to an increase in the Seebeck coefficient, leading to an increase in ZT in some semiconductors ${ }^{107,108,109,110}$. Simonson et al ${ }^{111}$ first
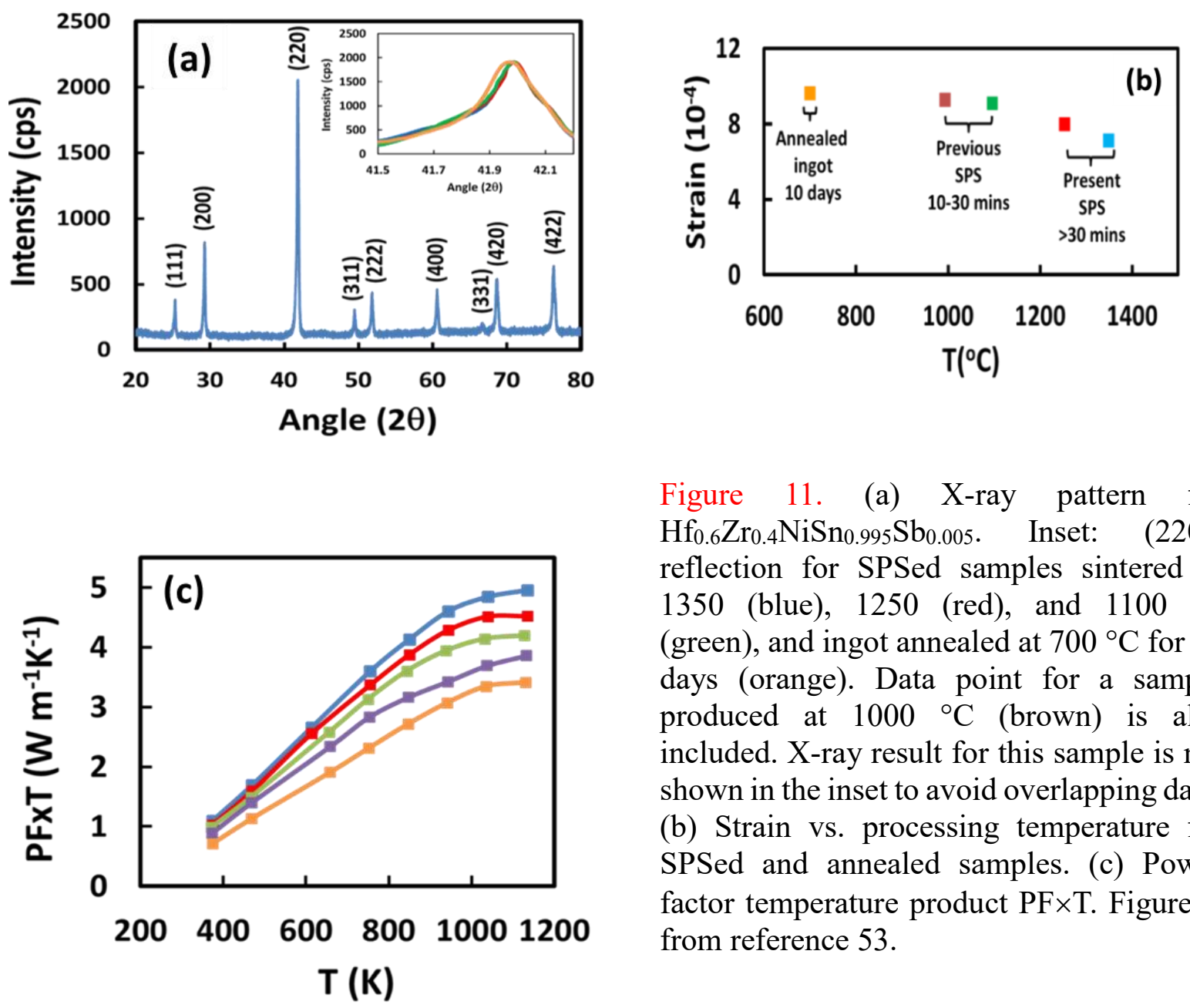

Figure 11. (a) X-ray pattern for $\mathrm{Hf}_{0.6} \mathrm{Zr}_{0.4 \mathrm{NiSn}} \mathrm{N}_{0.95} \mathrm{Sb}_{0.005}$. Inset: (220)reflection for SPSed samples sintered at 1350 (blue), 1250 (red), and $1100{ }^{\circ} \mathrm{C}$ (green), and ingot annealed at $700{ }^{\circ} \mathrm{C}$ for 10 days (orange). Data point for a sample produced at $1000{ }^{\circ} \mathrm{C}$ (brown) is also included. X-ray result for this sample is not shown in the inset to avoid overlapping data. (b) Strain vs. processing temperature for SPSed and annealed samples. (c) Power factor temperature product $\mathrm{PF} \times \mathrm{T}$. Figure is from reference 53.

reported evidence of resonant states by doping half-Heusler compound $\mathrm{Hf}_{0.75} \mathrm{Zr}_{0.25} \mathrm{NiSn}$ with vanadium. The results are highlighted in Figure 12. Carrier density, mobility, effective mass, and magnitude of Seebeck coefficient at room temperature are shown as the concentration of vanadium is increased to near $0.8 \%$. The resonant states scenario is corroborated by the observed correlation between increase in Seebeck coefficient, decrease in carrier concentration, and increase in effective mass. In particular, the correlation between enhanced Seebeck coefficient and increased DoS was confirmed by specific heat measurement.

Following the finding of Simonson, Chen et al explored improvement of TE properties by doping n-type $\mathrm{Hf}_{0.6} \mathrm{Zr}_{0.4} \mathrm{NiSn}_{0.995} \mathrm{Sb}_{0.005}$ that already showed $\mathrm{ZT}>1$ with the VA group elements vanadium, niobium, and tantalum $(\mathrm{V}, \mathrm{Nb} \text {, and } \mathrm{Ta} \text {, respectively })^{92}$. Alloys of 
$\left(\mathrm{Hf}_{0.6} \mathrm{Zr}_{0.4}\right)_{1-x} \mathrm{M}_{x} \mathrm{NiSn}_{0.995} \mathrm{Sb}_{0.005}(\mathrm{M}=\mathrm{V}, \mathrm{Nb}, \mathrm{Ta})$, where $x=0.002,0.005$, and 0.01 were investigated and their TE properties of these doped samples are shown in Figure 13. V acted as a resonant dopant, while $\mathrm{N}$ and Ta acted as regular dopants based on their TE properties measured. Both $\rho$ and $\mathrm{S}$ of the $\mathrm{V}$-doped samples were found to increase relative to those of undoped ones,

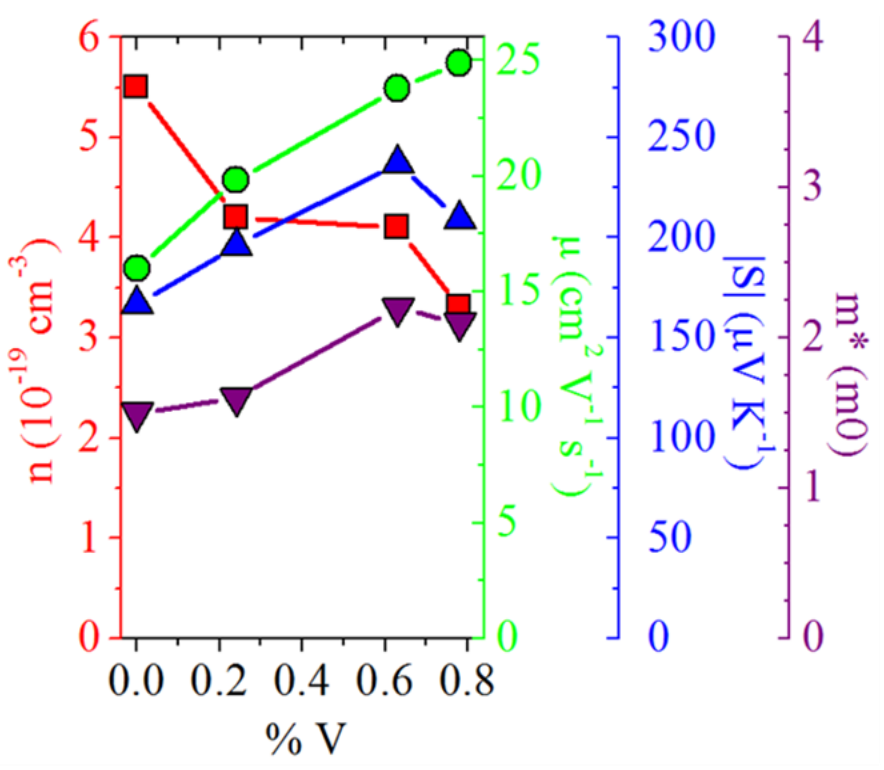

Figure 12: Carrier concentration (first axis, red squares), carrier mobility (second axis, green circles), magnitude of Seebeck coefficient (third axis, blue upward triangles), and carrier effective mass (fourth axis, purple downward triangles) of $\mathrm{V}$-doped $\mathrm{Hf}_{0.75} \mathrm{Zr}_{0.25} \mathrm{NiSn}$ as a function of $\mathrm{V}$ concentration. All values were either measured $(\mathrm{S})$ at room temperature or computed (n, $\left.\mu, m^{*}\right)$ from room temperature data. Figure and caption are from reference 111 .

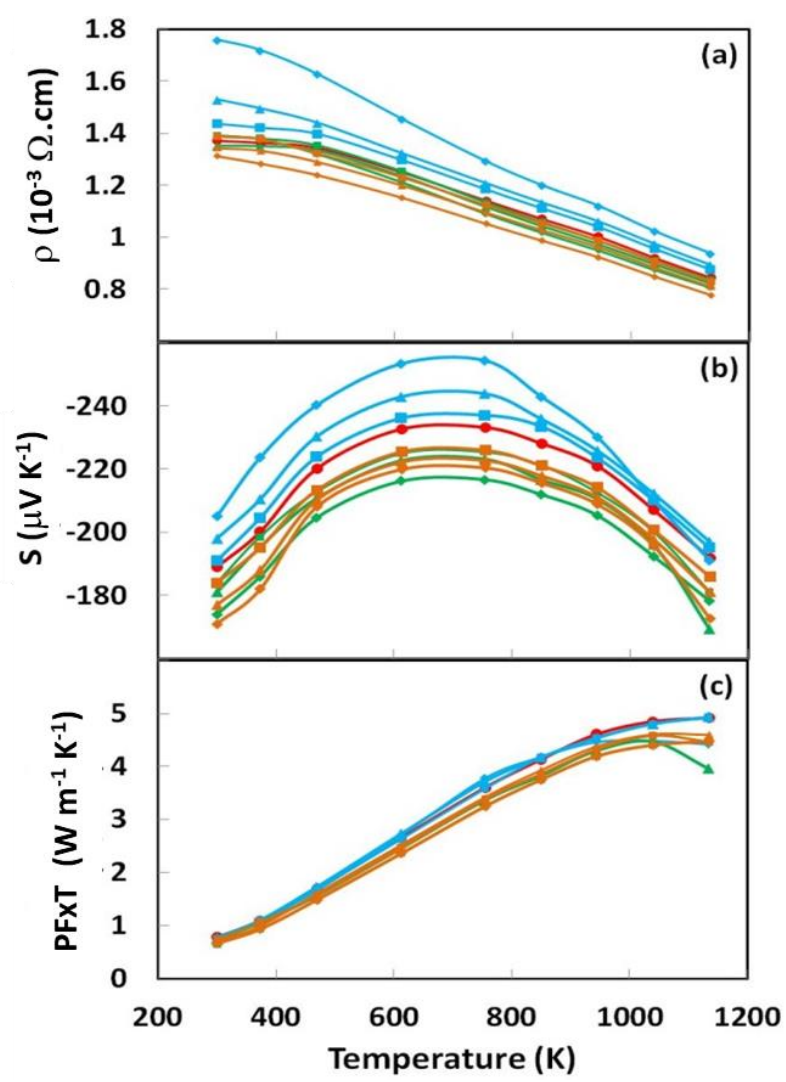

Figure 13. (a) Electrical resistivity, (b) thermopower, and (c) power factor times temperature for $\mathrm{M}=\mathrm{V}, \mathrm{Nb}$, Ta doped $\left(\mathrm{Hf}_{0.6} \mathrm{Zr}_{0.4}\right)_{1-x} \mathrm{M}_{x} \mathrm{NiSn}_{0.995} \mathrm{Sb}_{0.005 .} x=0$ (red circle); V: $x=0.002$ (blue square), 0.005 (blue triangle), 0.01 (blue rhombus); $\mathrm{Nb}: x$ $=0.002$ (green square), 0.005 (green triangle), 0.01 (green rhombus); Ta: $x=$ 0.002 (orange square), 0.005 (orange triangle), 0.01 (orange rhombus). Overlaps occur in the power factor plots. Figure and captions are from reference 92 . 
while $\kappa$ decreased due to the increase in $\rho$. The power factor of $\mathrm{V}$-doped samples remained the same as the undoped compounds, resulting in a high ZT of 1.3 near $850 \mathrm{~K}$ for $\left(\mathrm{Hf}_{0.6} \mathrm{Zr}_{0.4}\right)_{0.99} \mathrm{~V}_{0.01} \mathrm{NiSn}_{0.995} \mathrm{Sb}_{0.005}$ due to the decrease in $\kappa$. In contrast, $\mathrm{Nb}$ and $\mathrm{Ta}$ doped samples showed an opposite trend, as noted in the decrease in $\rho$ and $S$, and the power factor also decreased. The increased ZT in V doped samples concomitant with the reduced carrier concentration and increased band mass underscores a band-structure mechanism of ZT enhancement. More recently, beneficial TE transport properties (increased $\mathrm{S}$ and decreased $\kappa$ ) and enhancement of ZT, the latter by as much as $70 \%$, was found in $\mathrm{V}$ doped $\mathrm{ZrNiSn}$ in comparison with the undoped compound ${ }^{112}$. The authors discussed their results in light of $\mathrm{V}$ induced resonant states near the Fermi level. The cost effectiveness of Hf-free high ZT half-Heusler compounds was also pointed out.

(iii) High ZT via band engineering and soft phonons - In 2015, Fu et al discovered FeNbSbbased p-type half-Heusler compounds with heavy hole band ${ }^{94,113}$. The authors reported a large effective band mass near 7 to $10 \mathrm{~m}_{\mathrm{e}}$ for the new compounds, significantly higher than those reported for other high-performance TE materials. As shown in Figure 14 (a), the high density of states from the narrow hole band enables FeNbSb to accommodate a high doping level. The ultimate benefit to the thermoelectric properties is that the high content of heavy-mass dopant such as Hf optimizes the power factor, simultaneously reducing the lattice thermal conductivity due to the enhanced point-defect scattering. Figure 14 (b) shows a high effective mass, high power factor, and high doping level, all occurring in the same compound. A record high ZT of 1.5 for p-type $\mathrm{HH}$ compound was obtained at $1200 \mathrm{~K}$ upon substituting $\mathrm{Nb}$ with $12-14 \%$ of $\mathrm{Hf}$.

FeNbSb based compounds were also studied by other groups. Guo et al observed phase separation in FeTiNbSb, which seems to be a common feature of $\mathrm{HH}$ compounds with atomic size mismatch $^{114}$. He et al reported a record high power factor of $\sim 100 \mu \mathrm{W} / \mathrm{cm}-\mathrm{K}^{2}$ (or power factor temperature product of $\sim 3 \mathrm{~W} / \mathrm{m}-\mathrm{K}$ ) at room temperature ${ }^{115}$. First principles study of electronphonon interaction by Zhou et al revealed that the mechanism that led to remarkable high PF in $\mathrm{HH}$ compounds lied in the weakness of electron-acoustic deformation potential couplings ${ }^{116}$. These weak couplings originate from crystal symmetry-protected nonbonding orbitals at the band edge. It was emphasized by the authors that the vanishing bonding (antibonding) orbital interactions has made the half-Heuslers unique material platforms that bypass the traditional viewpoint. A more traditional approach to optimize $\mathrm{ZT}$ in $\mathrm{FeNbSb}$ was studied by Li et al ${ }^{117}$.
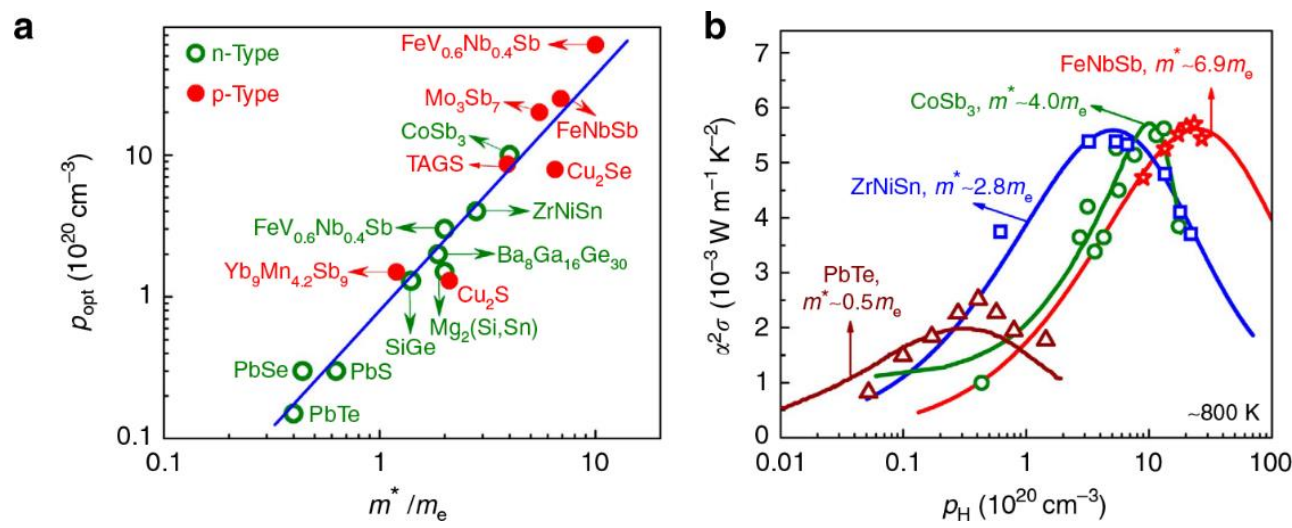
Figure 14. Comparison of transport character of light-band and heavy-band thermoelectric compounds. (a) The optimal carrier concentration $p_{o p t}$ is plotted against the density-of-state effective mass $\mathrm{m}^{*}$ for different thermoelectric compounds. The solid line is a guide for eyes. (b) Carrier concentration dependence of power factor for the typical light-band $\mathrm{PbTe}$, and the heavyband system: n-type $\mathrm{ZrNiSn}$, n-type filled $\mathrm{CoSb}_{3}$ and p-type FeNbSb near 800K. Figure and caption are from reference 94.

Recently, Zhu et al discovered new p-type half-Heusler compounds based on $\mathrm{ZrCoBi}^{95}$ and $\mathrm{TaFeSb}^{96}$ with record-high ZT of $\sim 1.42$ and 1.52 at $973 \mathrm{~K}$, respectively. ZT versus $\mathrm{T}$ of these compounds is shown in Figure 15. These HH compounds were discovered using the principle of inverse design of materials to search for high-ZT thermoelectric half-Heusler compounds with the required functionality and properties in mind. By adopting this approach, the authors discovered several unreported $\mathrm{HH}$ compounds. Among the latter were $\mathrm{ZrCoBi}$ and $\mathrm{TaFeSb}$ with relatively large bandgaps $(\sim 0.5 \mathrm{eV})$ and high band degeneracy. The outstanding thermoelectric performance was attributed to the unique band structure with a high band degeneracy $\left(\mathrm{N}_{\mathrm{v}}\right)$ of 10 and 8 in the two compounds, respectively. This finding is highlighted in Figure 16. The outstanding performance also benefited from lower mean sound velocity (softer phonons) that resulted in low thermal conductivity. Defect scattering due to additions of elements with lighter atomic mass and atomic size mismatch also contributes to the lowering of $\kappa_{\mathrm{L}}$.

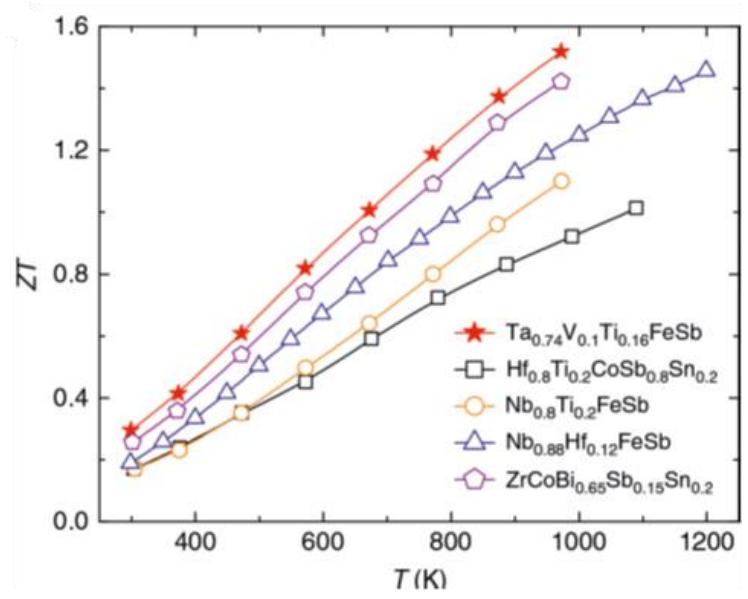

Figure 15. Comparison of the ZT between $\mathrm{Ta}_{0.74} \mathrm{~V}_{0.1} \mathrm{Ti}_{0.16} \mathrm{FeSb}$ and the other state-ofthe-art p-type half-Heuslers. Figure and caption are from reference 96.

\subsection{Power-conversion efficiency of TE modules based on state-of-the-art HH materials}

As mentioned in section 4.2, earlier study reported a power-conversion efficiency $\eta$ near $9 \%$ in TEGs built with Gen-2 HH materials. TEGs based on Gen-3 materials have an ideal conversion efficiency $\eta>10 \%$, and as high as $15 \%{ }^{95,96}$. However, only unileg devices have been tested. $\eta$ reached $11.4 \%$ in one material ${ }^{95}$, and power density was $9 \mathrm{~W} / \mathrm{cm}^{2}$ in another material ${ }^{96}$. Thus, the power density has not exceeded previously reported value using Gen-2 half-Heusler materials ${ }^{72}$. The fact that $\eta$ falls significantly below ideal values indicates the need to address outstanding materials science and device fabrication problems. 
a

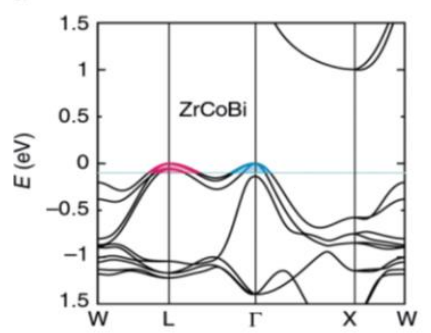

c

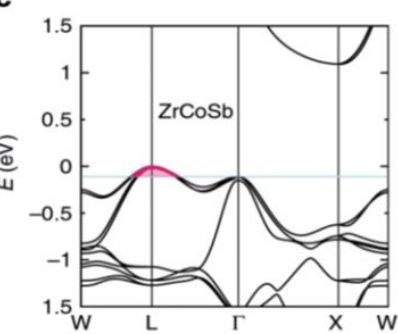

5.3

e

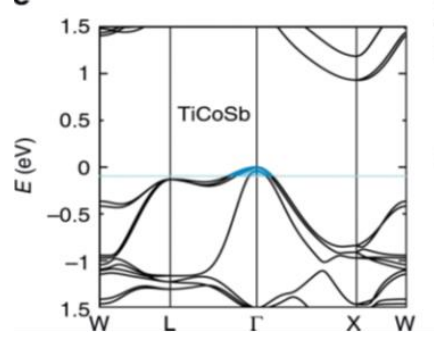

\section{b}

$\mathrm{ZrCoBi}$

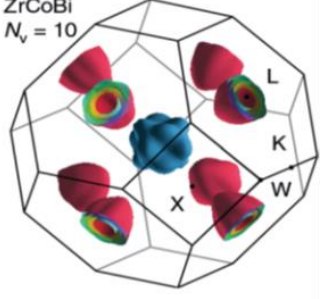

d

$\mathrm{ZrCoSb}$

$\mathrm{ZrCOSb}$
$N_{\mathrm{v}}=8$

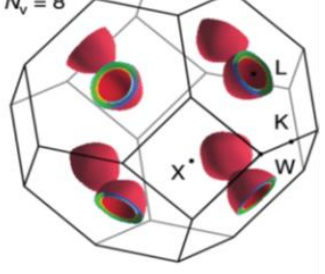

f

TiCosb

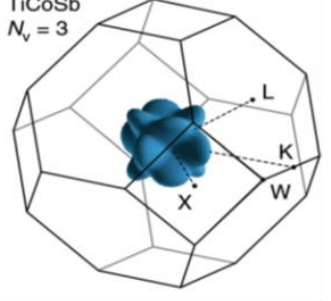

Figure 16. First-principle calculation of band structure. Calculated band structures of $\mathrm{ZrCoBi}$ (a), $\mathrm{ZrCoSb}$ (c), and $\mathrm{TiCoSb}$ (e). The blue lines represent energy level of $0.1 \mathrm{eV}$ below VBM. The corresponding iso-energy surfaces at $0.1 \mathrm{eV}$ below VBM in Brillouin zone of $\mathrm{ZrCoBi}$ (b), $\mathrm{ZrCoSb}$ (d), and $\mathrm{TiCoSb}$ (f). Figure and caption are from reference 95 .

\subsection{Looking ahead}

The vast compositional possibilities for half-Heusler compounds will continue to provide opportunities for optimizing TE properties through design of electronic and phononic structures. Besides the above-mentioned high ZT half-Heusler materials, recent result of $\mathrm{ZT} \sim 1$ in $\mathrm{NbCoSb}$ with valence electron count (VEC) of 19 has opened a pathway for searching for new compositions based on the valence balanced principle ${ }^{118},{ }^{119}$. The high ZT was found to occur in defect stabilized $\mathrm{Nb}_{\sim 0.8} \mathrm{CoSb}$, the ground state structure of VEC-19 $\mathrm{NbCoSb}$. Today, various high-throughput methods are utilized in materials screening and design ${ }^{13,14,120}$. The predictive capability of these methods will continue to improve as the database expands and new computational algorithms are developed. Despite the positive outlook, important technical issues still need to be overcome in terms of materials transduction. The thermoelectric modules must survive under extended and cyclic mechanical and thermal stresses without the degradation of performance. As such, the halfHeusler materials must have fatigue endurance and some fracture toughness. When coupled with other thermoelectric materials to form a device, the $\mathrm{p}$ and $\mathrm{n}$ legs must also have compatible linear thermal expansion coefficients. Systematic investigation of the mechanical properties and thermal expansion of refractory half-Heusler compounds was reported by Rogl et al ${ }^{121}$. Fracture toughness of $\sim 2 \mathrm{MPa} \mathrm{m}^{1 / 2}$ and Poisson's ratio near 0.2 were obtained, indicating that refractory half-Heuslers have higher damage tolerance than ceramics. The materials showed linear thermal expansion coefficients comparable to skutterudites and clathrates. Earlier measurement of a p-type refractory half-Heusler compound showed similar elastic modulus and hardness ${ }^{122}$. 


\section{Conclusion}

Since the initial reports of bandstructure gap and high thermopower in half-Heusler compounds three decades ago, there has been growing interest in these compounds as prospective thermoelectric materials. Half-Heusler compounds show good thermal stability and can be produced in large quantities. Using half-Heusler compounds with only a moderate ZT 1, state-ofthe-art conversion efficiency near $9 \%$ and high power density output have been demonstrated in p-n couple modules. It is thus not surprising that in recent years, half-Heusler materials have garnered considerable attention in the thermoelectric community as promising TE materials in the intermediate-to-high temperature range. The interest in half-Heusler materials has stimulated new approaches to improve their thermoelectric properties. During the past few years, high ZT>1 reaching $\sim 1.5$ have been obtained by targeting structural order/disorder, microstructure, heavy band, high band degeneracy, and dopant resonant states. Thermoelectric conversion efficiency near $11 \%$ in some uni-leg demonstration devices has been reported. Despite the impressive progress made to date, however, many technical challenges remain in integrating current high ZT materials into practical devices.

1 Energy Flow Chart Released by Lawrence Livermore National Laboratory. Available online: https://flowcharts.llnl.gov/content/assets/images/charts/energy/energy_2011_world.png.

2 Johnson I, Choate W T and Davidson A 2008 Waste Heat Recovery. Technology and Opportunities in Us Industry; US DOE Industrial Technologies Program, BCS, Inc.: Laurel, MD, USA

3 Goldsmid H J Introduction to Thermoelectricity Vol. 121 (Springer, 2010)

4 Aliev F G, Belogoroklov A I, Brandt N B, Kozyrkov V V, Scolozdra R V and Stadnyk Yu V 1988 Pis 'Ma. V. Zh. Eksp. Teor. Fiz. 47151

5 Aliev F G, Brandt N B, Moschalkov V V, Kozyrkov V V, Scolozdra R V and Belogoroklov A I 1989 Z. Phy. B 75167

6 Aliev F G, Kozyrkov V V, Moschalkov V V, Scolozdra R V and Durezewski K 1990 Z. Phy. B 80353

7 Cook B A, Harringa J L, Tan Z S and Jesser W A 1996 Proc. ICT'96 IEEE Cat. No. 96 TH8169 p. 122

8 Kloc Ch, Fess K, Kaefer W, Riazi-Nejad K and Bucher E 1996 Proc. ICT'96 IEEE Cat. No. 96TH8169 p.155 
9 Ogut S and Rabe K M 1995 Phys. Rev. B 5110443

10 Cutler M and Mott N 1969 Phys. Rev. 1811336

11 Nolas G S, Sharp J and Goldsmid H J 2001 Thermoelectrics Basic Principles and New Materials Developments (Springer, Berlin, Heidelberg, 2001)

12 Bai Z, Shen L, Han G and Feng Y P 2102 SPIN 21230006

13 Carrete J, L Wu, Mingo N, Wang S and Curtarolo S 2014 Phys. Rev. X 4011019

14 Legrain F, Carrete J, van Roekeghem A, Madsen G K H and Mingo N 2018 J. Phys. Chem. B 122625

15 Ma J, Hegde V I, Munira K, Xie Y, Keshavarz S, Mildebrath D T, Wolverton C, Ghosh A W and Butler W H 2017 Phys. Rev. B 95024411

16 Zhang X, Yu L, Zakutayev A and Zunger A 2012 Adv. Funct. Mater. 221425

17 Graf T, Felser C and Parkin S P 2011 Prog. Solid State Chem. 391

18 Page A, Poudeu P F P and Uher C 2016 J Materiomics 2104

19 Bartholome K, Balke B, Zuckermann D, Koehne M, Mueller M, Tarantik K and Koenig J 2014 J. Electr. Mater. 431775

20 Uher C, Yang J, Hu S, Morelli D T and Meisner G P 1999 Phys. Rev. B 59, 8615

21 Hohl H, Ramirez A P, Goldmann C, Ernst G, Wolfing B and Bucher E 1999 J. Phys.: Condens. Matter 11, 1697

22 Bhattacharya S, Ponnambalam V, Pope A L, Alboni P N, Xia Y, Tritt T M and Poon S J 1999 Proc. ICT'99 IEEE Cat. No. 99 TH8407 p.336

23 Browning V M, Poon S J, Tritt T M, Pope A L, Bhattacharya S, Volkov P, Ponnambalam V and Ehrlich A C 1999 MRS Symp. Proc. 545403

24 Cook B A, Meisner G P, Yang J and Uher C 1999 Proc. ICT'99 IEEE Cat. No. 99TH8407 p.64

25 Mahanti S D, Larson P, Chung D Y, Sportouch S and Kanatzidis M G 1999 MRS. Symp. Proc. 54523

26 Poon SJ 2018 Metals 8989

27 He J and Tritt T M 2017 Science 3571369

28 Mao J, Liu Z, Zhou J, Zhu H, Zhang Q, Chen G and Ren Z 2018 Adv. Phys. 6769

29 Olvera A A, Moroz,N A, Sahoo P, Ren T, Bailey T P, Page,A A, Uher C and Poudeu P F P 2017 Energy Environ. Sci. 101668

30 Chen L. Zeng X, Tritt T M and Poon S J 2016 J. Electr. Mater. 455554

31 Kim H S, Liu W, Chen G, Chu C and Ren Z 2015 Proc. Nat. Acad. Sci. 1128205

32 Liu Z, Mao J, Sui J and Ren Z 2018 Energy Environ. Sci. 1123

33 Vining C B 2009 Nat. Mater. 883

34 Kushida K and Kuriyama K 2000 Jpn. J. Appl. Phys. 3977 
35 Pierre J, Kaprzyk S, Skolozdra R V and Kouacou M A 1998 J. Phys.: Condens. Matter 101013

36 Pierre J, Skolozdra R V, Tobola J, Kaprzyk S, Hordequin C, Kouacou M A, Karla I, Currat R and Lelievre-Beran E 1997 J. Alloys Compounds 262-263 101

37 Nanda B R K and Dasgupta I 2003 J. Phys. Condens. Matter 157307

38 Offernes L, Ravindran P and Kjekshus A 2007 J Alloys Compounds 43937

39 Simonson J W and Poon S J 2008 J. Phys. Condens. Matter 20, 255220

40 Romaka V A, Shelyapina M G, Gorelenko Y K, Fruchart D, Stadnyk Y V, Romaka L P and Ckeurin V F 2006 Semiconductors 40655

41 Nanda B R K and Dasgupta I 2005 J. Phys. Condens. Matter 17, 5037

42 Galanakis I and Mavropoulos Ph 2007 J. Phys.: Condens Matter 19315213

43 Xie W, Weidenkaff A, Tang X, Zhang Q, Poon S J and Tritt T M 2012 Nanomater. 2379

44 Chen S and Ren Z 2013 Mater. Today 16387

45 Bhattacharya S, Pope A L, Littleton IV R T, Tritt T M, Ponnambalam V, Xia Y and Poon S J 2000 Appl. Phys. Lett. 772476

46 Poon S J 2001 Semicond. Semimet. 7037

47 Yu C, Zhu T-J, Shi R Z, Zhang Y, Zhao X-B and He J 2009 Acta Mater. 572757

48 Yu C, Zhu T J, Xiao K, Shen J J, Yang S H and Zhao X B 2010 J. Electron. Mater. 392008

49 Sekimoto T, Kurosaki K, Muta H and Yamanaka S 2006 Mater. Trans. 471445

50 Muta H, Kanemitsu T, Kurosaki K and Yamanaka S 2009 J. Alloys Compd. 46950

51 Sakurada S and Shutoh N 2005 Appl. Phys. Lett. 860821

52 Culp S R, Simonson J W, Poon S J, Ponnambalam V, Edwards J and Tritt T M 2008 Appl. Phys. Lett. 93022105

53 Chen L, Gao S, Zeng X, Dehkordi A M, Tritt T M and Poon S J 2015 Appl. Phys. Lett. 107 041902

54 Sportouch S, Larson P, Bastea M, Brazis P, Ireland, Kannenwurf, Mahanti S D, Uher C and Kanatzidis M G 1999 MRS. Symp. Proc. 545421

55 Xia Y, Bhattacharya S, Ponnambalam V, Pope A L, Poon S J and Tritt T M 2000 J. Appl. Phys. 881952

56 Culp S R, Simonson J W, Poon S J, Ponnambalam V, Edwards J and Tritt T M 2006 Appl. Phys. Lett. 88, 042106

57 Nolas G, Poon S J and Kanatzidis M 2006 MRS Bull. 311

58 Culp S R, Poon S J, Hickman N, Tritt T M and Blumm J 2008 Appl. Phys. Lett. 93022105

59 Shen Q, Chen L, Goto T, Hirai T, Yang J, Meisner G P and Uher C 2001 Appl. Phys. Lett. 79 4165

60 Yang J, Meisner G P and Chen L 2004 Appl. Phys. Lett. 851140 
61 Liu Y, Fu C, Xia K, Yu J, Zhao X, Pan H, Felser C and Zhu T 2018 Adv. Mater. 301800881

62 Bhattacharya S, Tritt T M, Xia Y, Ponnambalam V, Poon S J and Thadhani N 2002 Appl. Phys. Lett. 8143

63 Yan X, Joshi G, Liu W, Lan Y, Wang H, Lee S, Simonson J W, Poon S J, Tritt T M, Chen G and Ren Z F 2011 Nano Lett. 11556

64 Joshi G, Yan X, Wang H, Liu W, Chen G and Ren Z F 2011 Adv. Energy Mater. 1643

65 Populoh S, Aguirre M H, Brunko O C, Galazka K, Lu Y and Weidenkaff A 2012 Scripta Mater. 661073

66 Rausch E, Balke B, Ouardib S and Felser C 2014 Phys. Chem. Chem. Phys. 1625258

67 Schwall M and Balke B 2013 Phys. Chem. Chem. Phys. 151868

68 Nguyen V D, Rahman J U, Pham T H, Shin W H, Seo W-S, Kim M H and Lee S 2019 Acta Mater. 166650

69 Guzik M N, Echevarria-Bonet C, Riktor M, Carvalho P A, Gunnaes A E, Sorby M H and Hauback B 2018 Acta Mater. 148216

70 G“urth M, Rogl G, Romaka V V, Grytsiv A, Bauer E Rogl P 2016 Acta Mater. 104210

71 Berche A, Tedenac J C and Jund P 2017 Scripta Mater. 139122

72 Poon S J, Wu D, Zhu S, Xie W, Tritt T M, Thomas P and Venkatasubramanian R 2011 J. Mater. Res. 262795

73 Xie H H, Yu C, Zhu T J, Fu C G, Snyder G J and Zhao X B 2012 Appl. Phys. Lett. 100254104

74 Yan X, Liu W, Chen S, Wang H, Zhang Q, Chen G and Ren Z 2013 Adv. Energy Mater. 31195

75 Joshi G, Dahal T, Chen S, Wang H, Shiomi J, Chen G and Ren Z 2013 Nano Energy 282

76 Chen S, Lukas K C, Liu W, Opeil C P, Chen G and Ren Z 2013 Adv. Energy Mater. 31210

77 Yu C, Zhu T J, Xiao K, Shen J J, Yang S H and Zhao X B 2010 J. Electron. Mater. 392008

78 Yu C, Xie H, Fu C, Zhu T and Zhao X 2012 J. Mater. Res. 272457

79 Huang L, Zhang Q, Yuan B, Lai X, Yan X and Ren Z 2016 Mater. Res. Bull. 76107

80 Liao B and Chen G 2015 Mater. Res. Bull. 40746

81 Biswas K, He J, Blum I D, Wu C-I, Hogan T P, Seidman D N, Dravid V P and Kanatzidis M G 2012 Nature 489414

82 Pichanusakorn P and Bandaru P 2010 Mat. Sci. Eng. R 6719

83 Heremans J P, Thrush C M and Morelli D T 2004 Phys. Rev. B 70115334

84 Kishimoto K, Tsukamoto M and Koyanagi T 2002 J. Appl. Phys. 925331

85 Nishio Y and Hirano T 1997 J. Appl. Phys. 36170

86 Faleev S V and Leonard F 2008 Phys. Rev. B 77214304

87 Dehkordi A M, Zebarjadi M, He J and Tritt T M 2015 Mater. Sci. Eng. R 971 
88 Xie W J, He J, Zhu S, Su X L, Wang S Y, Holgate T, Graff J W, Ponnambalam V, Poon S J, Tang X F, Zhang Q J and Tritt T M 2010 Acta Mater. 584705

89 Makongo J P A, Misra D K, Zhou X, Pant A, Shabetai M R, Su X, Uher C, Stokes K L and Poudeu P F P 2011 J. Am. Chem. Soc.133 18843

90 Chen L D, Huang X Y, Zhou M, Shi X and Zhang W B 2006 J. Appl. Phys. 99064305

91 Cook B A, Chen T E, Dezsi G, Thomas P, Koch C C, Poon S J, Tritt T and Venkatasubramanial R 2015 J. Electr. Mater. 441936

92 Chen L, Liu Y, He J, Tritt T M and Poon S J 2017 AIP Adv. 7065208

93 Rogl G, Sauerschnig P, Rykavets Z, Romaka V V, Heinrich P, Hinterleitner B, Grytsiv A, Bauer E and Rogl P 2018 Acta Mater. 131336

94 Fu C, Bai S, Liu Y, Tang Y, Chen L, Zhao X and Zhu T 2015 Nat. Commun. 68144

95 Zhu H, He R, Mao J, Zhu Q, Li C, Sun J, Ren W, Wang Y, Liu Z, Tang Z, Sotnikov A, Wang Z, Broido D, Singh D J, Chen G, Nielsch K and Ren Z 2018 Nat. Commun. 92497

96 Zhu H, Mao J, Li Y, Sun J, Wang Y, Zhu Q, Li G, Song Q, Zhou J, Fu Y, He R, Tong T, Liu Z, Ren W, You L, Wang Z, Luo J, Sotnikov A, Bao J, Nielsch K, Chen G, Singh D J and Ren Z 2019 Nat. Commun. 10270

97 Kimura Y and Chai Y W 2014 JOM 61233

98 Berche A and Jund P 2018 Materials 11 868+

99 Miyamoto K, Kimura A, Sakamoto K, Ye M, Cui Y, Shimada K, Namatame H, Taniguchi M, Fujimori S, Saitoh Y, Ikenaga E, Kobayashi K, Tadano J and Kanomata T 2008 Appl. Phys. Exp. 1081901

100 Qiu P, Ynag J, Huang X, Chen X and Chen L 2010 Appl. Phys. Lett. 201096152105

101 Kirievsky K, Gelbstein Y and Fuks D 2013 J. Solid State Chem. 203247

102 Xie H, Wang H, Fu C, Liu Y, Snyder G J, Zhao X and Zhu T 2014 Sci. Rep. 46888

103 Kim K S, Kim Y M, Mun H, Kim J, Park J, Borisevich A Y, Lee K H and Kim S W 2017 Adv. Mater. 291702091

104 Fang T, Zhao X and Zhu T 2018 Materials 11847

105 Barczak S A, Buckman Jim, Smith R I, Baker A R, Don E, Forbes I and Bos J-W G Materials 201811536

106 Tang Y, Li X, Martin L H, Reves E C, Ivas T, Leinenbach C, Anand S, Peters M, Snyder G $\mathrm{J}$ and Battaglia C 2018 Energy Environ. Sci. 11311

107 Heremans J P, Jovovic V, Toberer E S, Saramat A, Kurosaki K, Charoenphakdee A, Yamanaka S and Snyder, G J 2008 Science 321554

108 Lee J H, Wu J and Grossman J C 2010 Phys. Rev. Lett. 104016602

109 Bilc D, Mahanti S D, Quarez E, Hsu K-F, Pcionek R and Kanatzidis M G 2004 Phys. Rev. Lett. 93146403 
110 Ahmad S, Hoang K and Mahanti S D 2006 Phys. Rev. Lett. 96056403

111 Simonson J W, Wu D, Xie W J, Tritt T M and Poon S J 2011 Phys. Rev. B. 83235211

112 Chauhan N S, Bathula S, Vishwakarma A, Bhardwaj R, Gahtori B, Kumar A and Dhar A 2018 ACS Appl. Energy Mater. 1757

113 Fu C, Zhu T, Liu Y, Xi H and Zhao X 2015 Energy Environ. Sci. 8216

114 Guo S, Yang K, Zeng Z and Zhang Y 2018 Phys.Chem.Chem.Phys. 2014441

115 He R, Kraemer D, Mao J, Zeng L, Jie Q, Lan Y, Lie C, Shuai J, Kim H S, Liu Y, Broido D, Chua C-W, Chen G and Ren Z 2016 PNAS 11313576

116 Zhou J, Zhu H, Liu T-H, Song Q, He R, Mao J, Liu Z, Ren W, Liao B, Singh D, Ren Z and Chen G 2018 Nat. Commun. 91721

117 Li W, Yang G and Zhang J 2016 J. Phys. D: Appl. Phys. 49195601

118 Xia K, Liu Y, Anand S, Snyder G J, Xin J, Yu J, Zhao X and Zhu T 2018 Adv. Funct. Mater. 281705845

119 Anand S, Xia K, Hegde V I, Aydemir U, Kocevski V, Zhu T, Wolvertona C and Snyder G J 2018 Energy Environ. Sci. 111480

120 Gautier R, Zhang X, Hu L, Yu L, Lin Y, Sunde T O L, Chon D, Poeppelmeier K R and Zunger A 2015 Nat. Chem. 7308

121 Rogl G, Grytsiv A, Gürth M, Tavassoli A, Ebner C, Wünschek A, Puchegger S, Soprunyuk V, Schranz W, Bauer E, Müller H, Zehetbauer M and Rogl P 2016 Acta Mater. 107178

122 Gahlawat S, He R, Chen S, Wheeler L, Ren Z F and White K W 2014 J. Appl. Phys. 116 083516 